\title{
Autoimmunity in MFG-E8-deficient mice is associated with altered trafficking and enhanced cross-presentation of apoptotic cell antigens
}

\author{
YuFeng Peng ${ }^{1}$ and Keith B. Elkon ${ }^{1,2}$ \\ ${ }^{1}$ Division of Rheumatology and ${ }^{2}$ Department of Immunology, University of Washington, Seattle, Washington, USA.
}

\begin{abstract}
Apoptotic cells must be rapidly cleared, as defects in this process can lead to autoimmunity. Milk fat globule EGF factor 8 (MFG-E8) binds to apoptotic cells and facilitates their removal through interaction with phagocytes. Mice deficient in MFG-E8 develop lupus-like autoimmunity associated with accumulation of apoptotic cells in vivo. Here, we have shown that MFG-E8 controls phagocytic ingestion of cell fragments as well as their intracellular processing into MHC-antigen complexes. Older $M f g e 8^{-/}$mice spontaneously developed dermatitis associated with $\mathrm{CD8}^{+} \mathrm{T}$ cell infiltration and striking activation of effector memory $\mathrm{CD8}^{+} \mathrm{T}$ cells. $\mathrm{CD8}^{+} \mathrm{T}$ cell responses to both exogenous and endogenous apoptotic cell-associated antigens were enhanced in $\mathrm{Mfge}^{-/-}$ mice. MFG-E8 deficiency accelerated the onset of disease in a mouse model of autoimmune diabetes. Enhanced $\mathrm{CD8}^{+} \mathrm{T}$ cell responses were attributed to increased cross-presentation by DCs along with increased detection of antigen-MHCI complexes. Intracellular trafficking analysis revealed that intact apoptotic cells ingested by wild-type DCs rapidly fused with lysosomes, whereas smaller fragments persisted in $\mathrm{Mfge \textrm {B } ^ { - / - }}$ DC endosomal compartments for 24 hours. These observations suggest that MFG-E8 deficiency promotes immune responses to self antigens not only by delaying the clearance of dying cells but also by altering intracellular processing, leading to enhanced self-antigen presentation.
\end{abstract}

\section{Introduction}

It is now well recognized from mouse models and increasing evidence in humans that defective clearance of apoptotic cells by classical phagocytes such as macrophages leads to systemic autoimmune disorders $(1,2)$. The fate of the remaining dead cell fragments and the mechanism or mechanisms by which they affect the adaptive immune system are key issues to address.

Apoptotic cells, in their particulate form, are far more efficient than soluble protein in delivering an antigen load to APCs (3). In addition, aggregation of self antigen on the surface of apoptotic cells can lower the threshold of B cell activation (4). In vivo, apoptotic cells are rapidly removed and are difficult to detect outside of phagocytes. Surface changes expose "eat me" signals for phagocytes (5). Translocation of phosphatidylserine (PS) to the cell surface membrane is a key early event that enables several different "bridging proteins" or serum opsonins (B2-glycoprotein, annexins, Gas6, protein S, and MFG-E8) to coat the apoptotic cell and facilitate clearance. In addition, other receptors and ligands that include early complement components, collectins, and integrins have been implicated in the recognition and/or removal of apoptotic cells (reviewed in ref. 5). The multiplicity of receptors and ligands may be explained by partial redundancy, compartmentalization of different ligand/receptor pairs for different cell types, and the presence of inflammation. Finally, it is likely that some pairs are involved in adhesive interaction, whereas others stimulate phagocytosis (the "tether and tickle" model; ref. 6).

Conflict of interest: The authors have declared that no conflict of interest exists. Citation for this article: J Clin Invest. 2011;121(6):2221-2241. doi:10.1172/JCI43254.
Once ingested, intact apoptotic cells are swiftly digested through phagosome-lysosome fusion (7). When the clearance of apoptotic cells is delayed, as occurs in MFG-E8 deficiency, cells begin to disintegrate, including the formation of blebs and smaller cell fragments $(8,9)$. Although smaller cell fragments are also ingested by phagocytes, it is not known whether intact apoptotic cells and cell debris share the same fate inside phagocytes

One consequence of apoptotic cell ingestion is the production of immunosuppressive cytokines such as TGF- $\beta$ and IL-10 (10), whereas delayed clearance leads to postapoptotic necrosis and release of self molecules, such as uric acid heat shock proteins and HMGB-1, that promote inflammatory cytokine production (11, 12). In both macrophages and DCs, apoptotic cell uptake inhibits IL-12 production in response to LPS $(13,14)$. Although most studies have focused on the role of macrophages in the clearance of apoptotic cells, macrophages appear to fully digest apoptotic cell antigens and therefore appear to be less relevant to direct $\mathrm{T}$ cell tolerance (15). In contrast, DCs are highly efficient at processing and presentation of ingested antigen through either direct or cross presentation (16). Continuous uptake and presentation of antigen appears to be necessary to delete or anergize potentially self-reactive $\mathrm{CD}^{+} \mathrm{T}$ cells (17).

MFG-E8 (milk fat globule EGF factor 8, also known as lactadherin), a member of the discoidin family, was originally defined as a soluble milk protein but was subsequently shown by Nagata and colleagues to act as a bridging molecule between apoptotic cells and phagocytes $(18,19)$. It binds to PS exposed on apoptotic cells via its factor VIII homologous domains, C1 and C2, and to $\alpha_{v} \beta_{3}$ and $\alpha_{v} \beta_{5}$ integrins on phagocytes through an RGD motif on the second EGF domain. A recombinant protein with a RGD $\rightarrow$ RGE mutation 
A

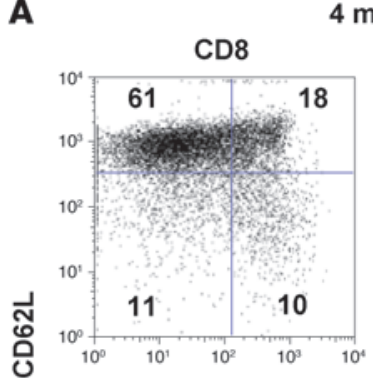

4 month
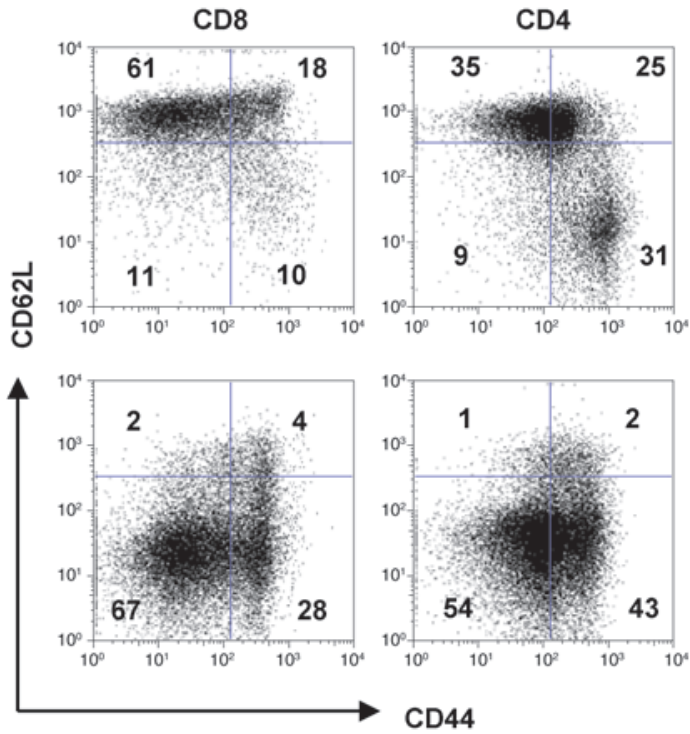

$\mathbf{B}$
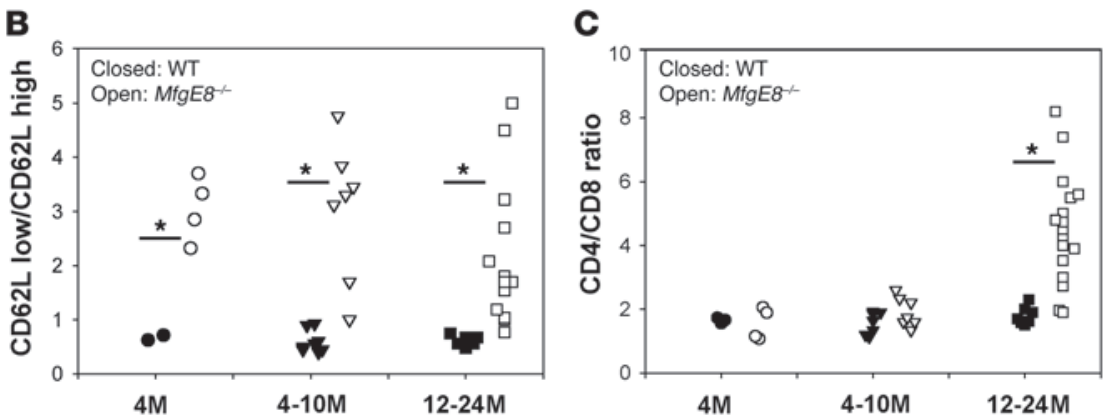

12 month
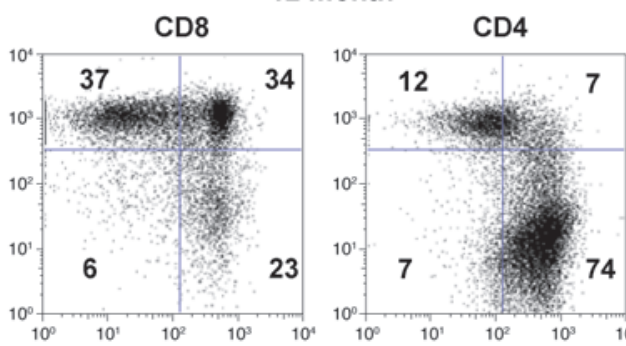

WT
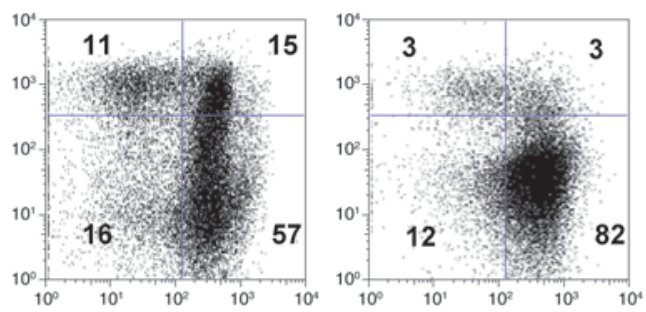

Mfges

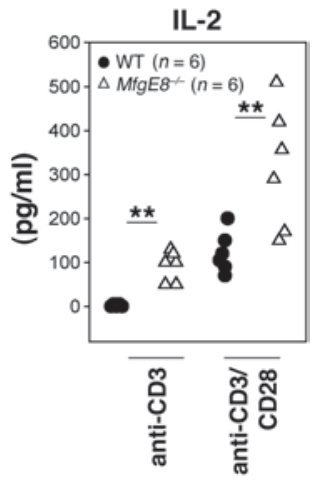

Figure 1

Increased frequency of $\mathrm{CD}_{2} \mathrm{~L}^{\mathrm{I}}{ }^{\circ} \mathrm{CD} 8$ effector memory T cells in $\mathrm{Mfge}^{-/-}$mice. (A) Splenic $\mathrm{CD}^{+}$and CD4+ ${ }^{+}$cells from 4- or 12-month-old WT or $\mathrm{Mfge}^{-/-}$mice were analyzed for the expression of CD44 and CD62L by flow cytometry. Representative of 4-12 mice in each group. The number in each quadrant shows the percentage of each population. (B) Summary of the ratios between $\mathrm{CD} 62 \mathrm{~L}^{10}$ and CD62 $\mathrm{L}^{\mathrm{hi}} \mathrm{CD} 44^{+} \mathrm{CD} 8^{+} \mathrm{T}$ cell population in either WT or Mfge $8^{-/-}$mice at different ages. ${ }^{*} P=0.02$ (C) The ratios between $\mathrm{CD} 4^{+}$and $\mathrm{CD} 8^{+} \mathrm{T}$ cells in either WT or Mfge $8^{-/-}$mice at different ages. ${ }^{*} P=0.02$. (D) Splenic CD8+ T cells were negatively selected from 9-month-old WT or Mfge $8^{-/-}$mice $(n=6)$ and $1 \times 10^{5} \mathrm{~T}$ cells stimulated with plate-bound anti-CD3 alone $(1 \mu \mathrm{g} / \mathrm{ml})$ or anti-CD3 plus anti-CD28 $(1 \mu \mathrm{g} / \mathrm{ml})$ for 3 days. The levels of IFN- $\gamma$ and IL-2 in the supernatant were evaluated by ELISA. ${ }^{\star \star} P=0.01$.

(D89E) acts as a dominant negative protein and prevents uptake of apoptotic cells by macrophages. Mice deficient in MFG-E8 on a mixed genetic background spontaneously developed lupus-like autoimmunity around 40 weeks of age, a phenotype that was partially recapitulated in WT mice by injection of the dominant negative recombinant protein (20). Since lupus is usually $\mathrm{T}$ cell driven, we analyzed T cells in MFG-E8-deficient mice on the C57BL/6 background. Although $\mathrm{CD}^{+} \mathrm{T}$ cells had an activated phenotype, this was much more pronounced in the $\mathrm{CD}^{+} \mathrm{T}$ cell subset. Further investigation revealed that $\mathrm{CD}^{+} \mathrm{T}$ cell activation was caused by altered processing and increased presentation of apoptotic cellassociated antigen in the absence of MFG-E8.

\section{Results}

MFG-E8 deficiency promotes the differentiation of $C D 62 L^{\text {lo }} \mathrm{CD} 8$ effector memory $T$ cells in the spleen. Mfge $8^{-1-}$ mice produce class-switched $\mathrm{IgG}$ autoantibodies, suggesting that $\mathrm{T}$ cells drive the lupus-like dis- ease that develops in these mice (18). Since T cells in these animals have not been systematically studied, we first quantified expression markers of chronic activation CD44 and CD62L on splenic T cells. Although the activation of splenic T cells was similar between 2-month-old WT and $M$ fge $8^{-/-}$mice (Supplemental Figure 1; supplemental material available online with this article; doi:10.1172/ JCI43254DS1), a striking downregulation of CD62L was observed in both $\mathrm{CD}^{+}$and $\mathrm{CD}^{+} \mathrm{T}$ cell populations in 4-month-old $\mathrm{Mfge}^{-/-}$ mice (Figure 1A). In mice greater than 12 months old, $\mathrm{CD}^{+} \mathrm{T}$ cells showed a similar increase of $\mathrm{CD} 62 \mathrm{~L}^{\text {lo }} \mathrm{CD} 44^{\text {hi }}$ population in both WT and $M$ fge $8^{-/-}$mice. In contrast, differences between WT and $M$ fge $^{-/-}$mice were observed in the $\mathrm{CD}^{+} \mathrm{T}$ cell population. Whereas the $\mathrm{CD} 62 \mathrm{~L}^{\text {lo }} \mathrm{CD} 44^{\text {hi }} \mathrm{CD}^{+} \mathrm{T}$ cell population remained constant in WT mice, the percentage was significantly increased in $\mathrm{Mfges}^{-/-}$ mice. Since the functional division of central and effector memory $\mathrm{CD}^{+} \mathrm{T}$ cells correlates with their CD62L expression (21), we compared the ratio between CD62 $\mathrm{L}^{\text {lo }}$ effector memory and CD62 L ${ }^{\text {hi }}$ cen- 
A
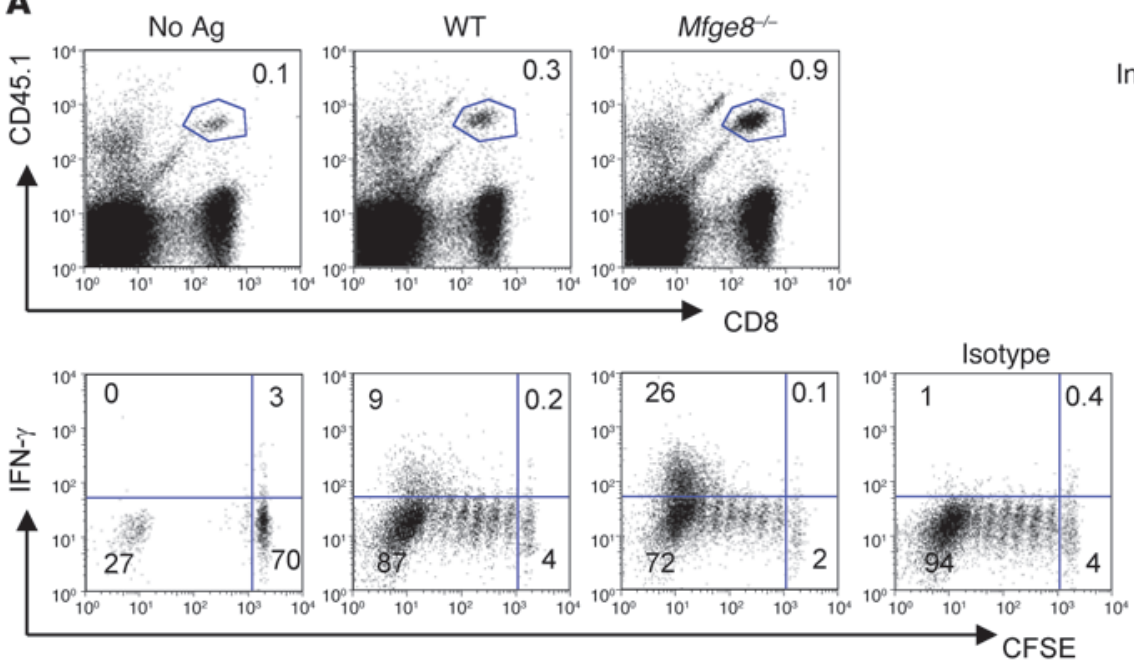

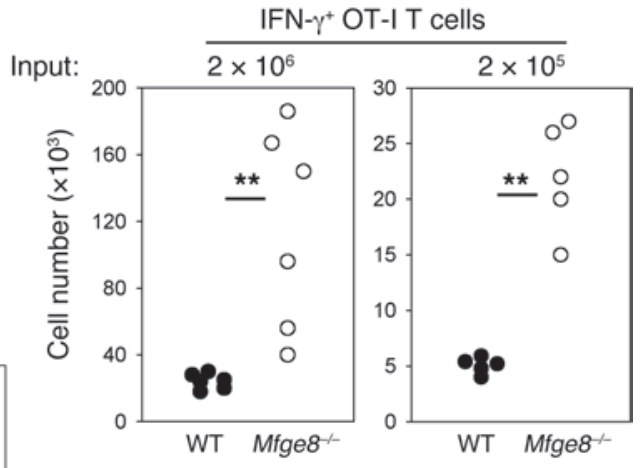

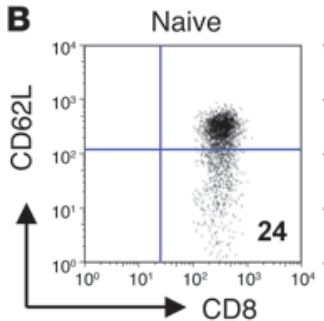

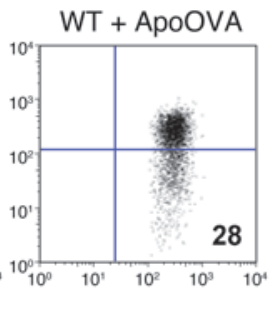

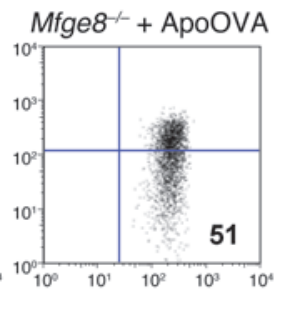

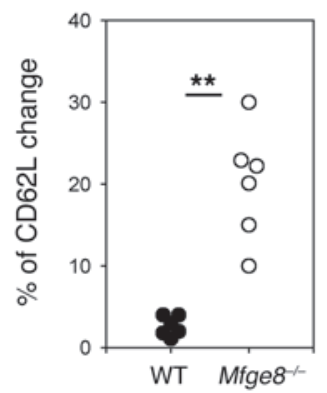

Figure 2

MFG-E8 deficiency enhances OT-I T cell effector function in response to apoptotic cell-associated antigen. (A) Left: either $2 \times 10^{6}$ or $2 \times 10^{5}$ CD45.1/CD45.2 CFSE-labeled OT-I T cells were transferred into 2-month-old WT or Mfge8 ${ }^{-/}$mice. 1 day later, the recipients were challenged with $20 \times 10^{6}$ Apo-OVA. At day 9 after OT-I transfer, spleen cells were restimulated with $1 \mu \mathrm{M}$ OVA peptide. OT-I T cells were gated using the congenic marker CD45.1, and the percentage of cells expressing IFN- $\gamma$ was evaluated by flow cytometry (lower left panel). The results shown are from mice that received $2 \times 10^{6}$ OT-I T cells and are representative of 5-6 mice in each group. The numbers in the dot plots of the upper panel are the percentages of OT-I T cells, and those in the lower panel show the percentages of each population. Right: summary of the absolute numbers of IFN- $\gamma$-producing OT-I T cells after transferring either $2 \times 10^{6}$ or $2 \times 10^{5}$ OT-I T cells. ${ }^{*} P<0.01$. (B) Left: OT-I T cells were challenged as in $\mathbf{A}$, and the level of CD62L expression was analyzed by flow cytometry at day 9 after challenge. No difference of CD62L expression on naive OT-I T cells was observed between WT and $\mathrm{Mfge}^{-/-}$recipients. The numbers in the dot plot denote the percentages of the CD62 $\mathrm{L}^{1}$ population. Right: after subtracting the percentage of CD62 $\mathrm{L}^{\circ}{ }^{\circ}$ cells in naive OT-I T cells, the change in the proportion of CD62L $\mathrm{L}^{10} \mathrm{OT}-\mathrm{I} \mathrm{T}$ cells induced by Apo-OVA in either WT or Mfge $8^{-1-}$ spleen is shown. ${ }^{* \star} P<0.01$.

tral memory cells among activated $\mathrm{CD} 44^{+} \mathrm{CD} 8^{+} \mathrm{T}$ cells. As shown in Figure 1B, the ratios of effector/central memory CD $44^{+} \mathrm{CD} 8^{+}$ $\mathrm{T}$ cells were significantly increased in $\mathrm{Mfges}^{-/}$mice of various ages. Furthermore, despite the fact that total spleen cell numbers were similar between $\mathrm{Mfges}^{-/-}$and WT mice, the ratios of $\mathrm{CD}^{+} / \mathrm{CD}^{+}$ $\mathrm{T}$ cells were significantly increased in old MFG-E8 mice (Figure 1C). The reduction in $\mathrm{CD}^{+} \mathrm{T}$ cell numbers was likely due to continuous activation-induced cell death (AICD) of $\mathrm{CD}^{+} \mathrm{T}$ cells (22). To determine whether the increased percentage of $\mathrm{CD} 62 \mathrm{~L}^{\text {lo }} \mathrm{CD}^{+}$ $\mathrm{T}$ cells in $\mathrm{Mfge}^{-/-}$has functional implications, we stimulated purified splenic $\mathrm{CD}^{+} \mathrm{T}$ cells from 9-month-old mice with either anti$\mathrm{CD} 3$ or anti-CD3/CD28 and compared their cytokine production. As shown in Figure 1D, upon activation, $\mathrm{CD}^{+} \mathrm{T}$ cells from $\mathrm{Mfge}^{-8^{-}}$ mice produced significantly more IFN- $\gamma$ and IL- 2 than WT mice. These results indicate that while both $\mathrm{CD}^{+}$and $\mathrm{CD} 8^{+} \mathrm{T}$ cells in MFG-E8-deficient mice are activated, the $\mathrm{CD}^{+}$population showed a much more striking activation profile, which was associated with a relative depletion of these cells in older mice.
MFG-E8 deficiency enhances $C D 8^{+} T$ cell responses to an apoptotic cell-associated antigen. $\mathrm{CD}^{+} \mathrm{T}$ cells may be activated by either environmental or self antigens. For antigens associated with apoptotic cells to be recognized by self-reactive $\mathrm{CD} 8^{+} \mathrm{T}$ cells, they have to be processed by APCs through cross-presentation (23). To determine whether increased $\mathrm{CD}^{+} \mathrm{T}$ cell activation in $\mathrm{Mfge}^{-/-}$mice can be explained by more efficient cross-presentation by splenic APCs, we compared the responses of adoptively transferred OT-I T cells to OVA-loaded apoptotic cells (Apo-OVA) in WT and $\mathrm{Mfge}^{-/-}$mice. We transferred CD45.1/CD45.2 OT-I CD8 ${ }^{+} \mathrm{T}$ cells into 2-monthold WT or Mfges $8^{-/}$mice and challenged the recipients with $20 \times 10^{6}$ Apo-OVA. Flow cytometry and immunofluorescence staining of spleen sections demonstrated a similar distribution of apoptotic cells in CD $11 \mathrm{~b}$ and CD $11 \mathrm{c}$ cells between WT and $\mathrm{Mfges}^{-/}$mice at 20 hours after injection (Supplemental Figure 2). At day 9 after stimulation, we analyzed the expansion and phenotype of OT-I T cells recovered from spleen. As shown in Figure 2A, 2- to 3-fold more OT-I T cells were recovered from $M f g e 8^{--}$mice, and they produced 
A

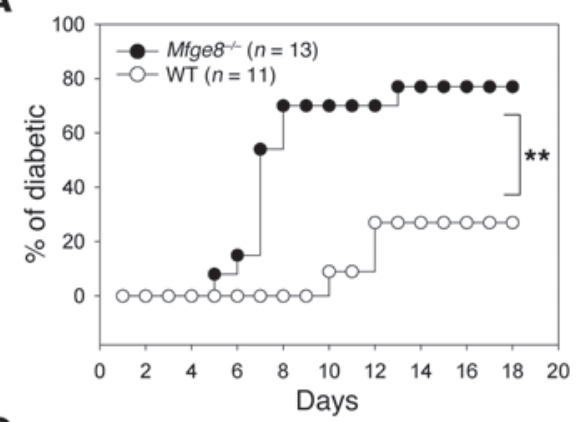

C
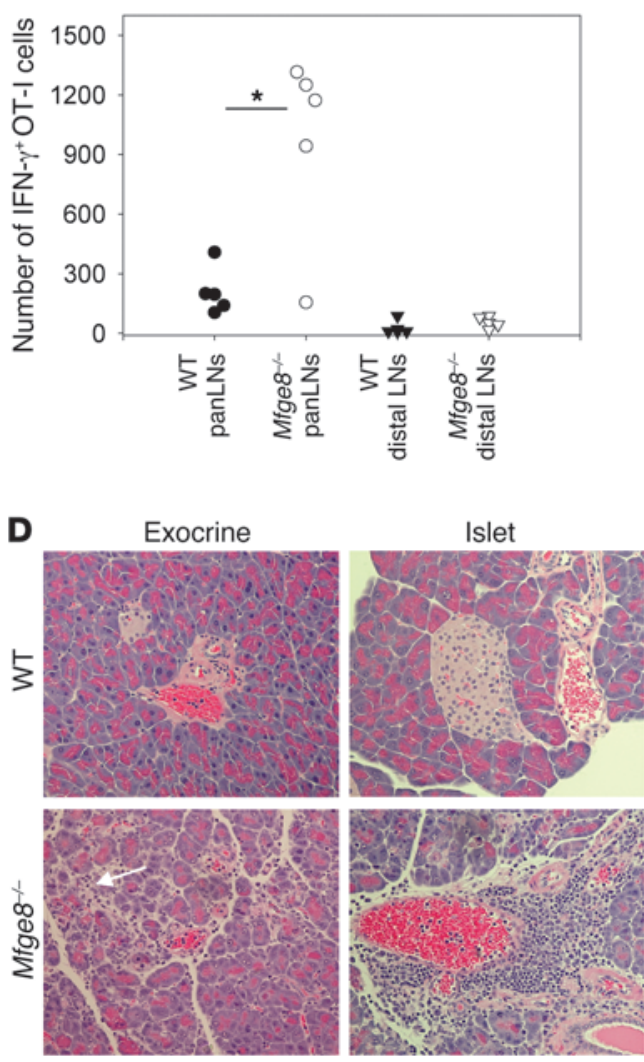

B

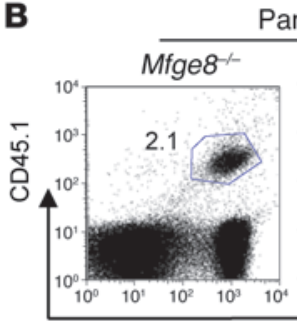

PanLNs
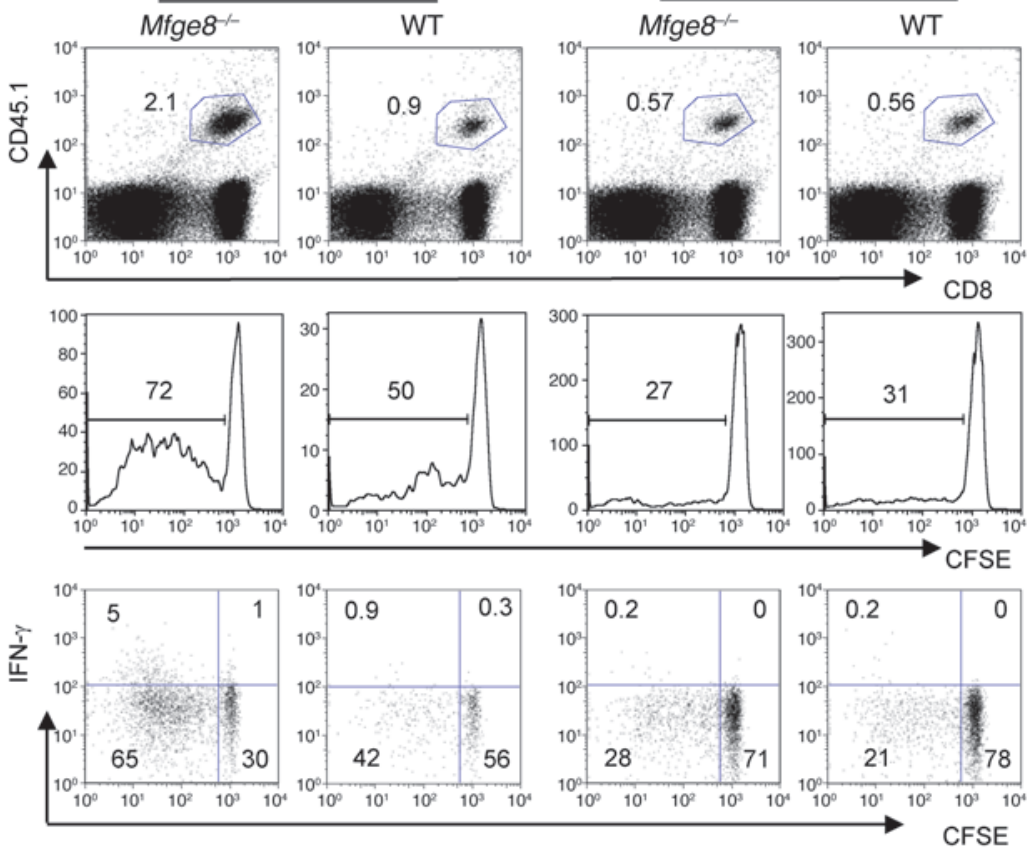

\section{Figure 3}

MFG-E8 deficiency enhances cross-presentation of endogenous OVA antigen. (A) $5 \times 10^{6}$ OT-I T cells were transferred into 2- to 4-month-old WT $(n=11)$ or Mfge $8^{-1-}$ RIP-mOVA $(n=13)$ mice. The frequency and the time of onset of diabetes are shown. ${ }^{* *} P=0.0001$. (B) $5 \times 10^{6}$ CD45.1/CD45.2 OT-I T cells were labeled with CFSE and transferred into 2-month-old WT or Mfge $^{-/-}$RIP-mOVA mice as in A. Lymphocytes from the pancreatic draining LNs (panLNs) and distal LNs were recovered at day 5 and restimulated with OVA peptide. Proliferation (middle panels) and expression of IFN- $\gamma$ by OT-I T cells (lower panels) were evaluated by flow cytometry. The dot plots are representative of 5 mice from each group. The numbers in the dot plots (upper panels) denote the percentages of OT-I T cells; those in the histogram (middle panels) show the percentages of dividing cells and those in the dot plots (lower panels) show the percentage of each population. (C) The absolute numbers of IFN- $\gamma-$ positive OT-I T cells recovered from draining or distal LNs are shown. ${ }^{*} P=0.01$. (D) H\&E staining of the pancreas from either WT or Mfge $8^{-/}$RIP-mOVA mice at day 7 after transfer of OT-I T cells. Note the intense infiltration of lymphocytes in both endocrine and exocrine (white arrow) tissues in the pancreas of $\mathrm{Mfge}^{-/-} \mathrm{RIP}-\mathrm{mOVA}$ mice. The results are representative of 5 mice in each group. Original magnifications, $\times 40$.
2- to 3-fold more IFN- $\gamma$ than those from WT mice. A similar difference was observed when 10-fold fewer OT-I T cells were transferred (Figure 2A). To determine the activation phenotype of OT-I T cells in $\mathrm{Mfge} \mathrm{8}^{-/-}$mice, we analyzed their CD62L expression. As shown in Figure 2B, whereas OT-I T cells recovered from WT mice expressed levels of CD62L similar to those of naive cells, 3- to 5-fold more CD62L $\mathrm{L}^{\text {lo }} \mathrm{OT}-\mathrm{I} \mathrm{T}$ cells were recovered from $\mathrm{M} f g \mathrm{~S}^{-/-}$mice, consistent with the above observations that MFG-E8 deficiency promoted the differentiation of CD8 effector memory cells. The increased activation of OT-I T cells was specific for apoptotic cell-associated antigen, since OT-I T cell responses to soluble OVA were similar between WT and $M$ fge $8^{-1-}$ mice (Supplemental Figure 3).

$M F G-E 8$ deficiency enhances OT-I T cell response to endogenous antigen in RIP-mOVA model resulting in diabetes. Since a bolus injection of apoptotic cells might exceed the physiological clearance capacity of splenic macrophages, we next asked whether MFG-E8 deficiency would promote the cross-presentation of an endogenous antigen. To this end, we crossed $M f g e 8^{-/-}$with RIP-mOVA mice to create $M$ fge $^{-/-}$RIP-mOVA mice. In RIP-mOVA mice, OVA antigen is specifically expressed in the pancreatic islets and distal tubules in the kidney (24). Transferred OT-I T cells can be activated in the pancreatic draining lymph nodes by migrating APCs that have captured apoptotic islet cells. Once activated, OT-I T cells infiltrate the islets and induce diabetes (24). To determine whether OT-I T cells become more efficiently activated in the absence of MFG-E8, we transferred $5 \times 10^{6}$ OT-I T cells to 2- to 4-month-old WT or $M f g e 8^{-/-}$RIP-mOVA mice. As shown in Figure 3A, a higher frequency and faster onset of diabetes were observed in $M$ fge $8^{-/-}$ RIP-mOVA mice. When OT-I T cells were recovered from either draining or distal LNs and restimulated with OVA peptide in vitro, higher numbers of IFN- $\gamma$-producing OT-I T cells were recovered in cells obtained from the draining LNs of $\mathrm{Mfge}^{-1-} \mathrm{RIP}-\mathrm{mOVA}$ mice (Figure 3, B and C). Consistent with the enhanced $\mathrm{CD}^{+}$effector $\mathrm{T}$ cell function, intensive lymphocyte infiltration was observed in both islet and exocrine tissue from $M f g e 8^{-/-}$RIP-mOVA mice (Figure $3 \mathrm{D})$. Since OVA is also expressed in the tubules of the kidney in 
A
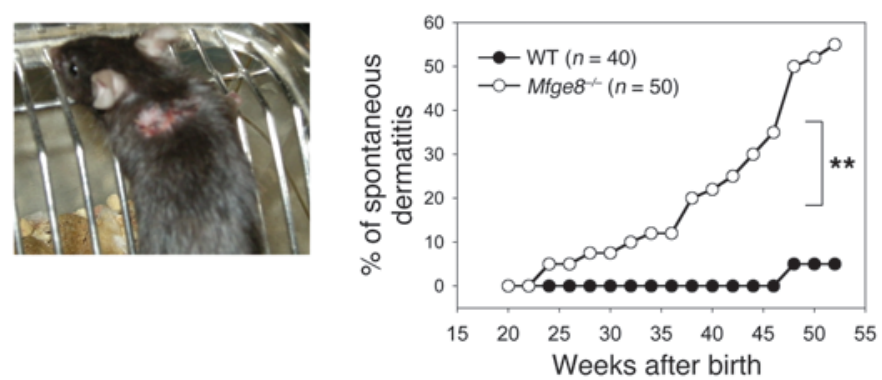

B
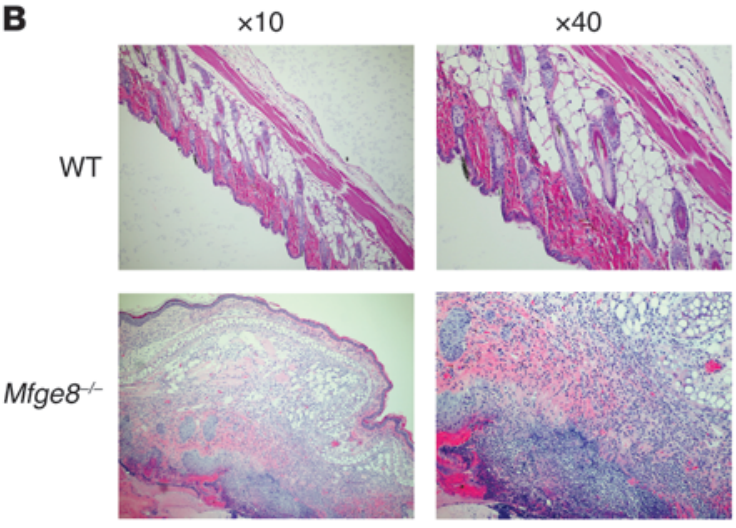

$\times 10$
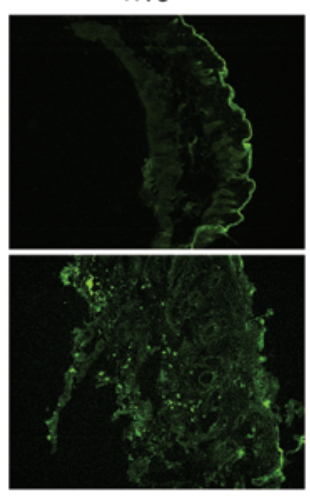

C
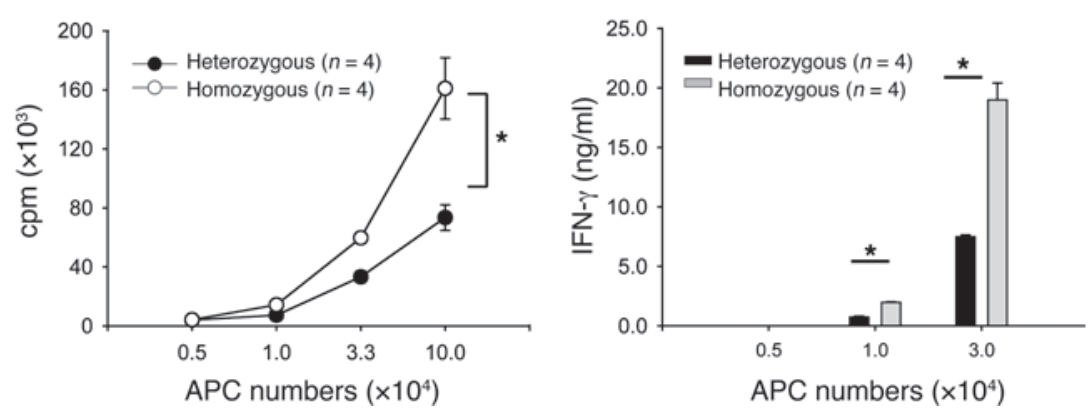

\section{Figure 4}

MFG-E8 deficiency increases cross-presentation of a skin antigen by APCs. (A) The gross appearance, frequency, and time of onset of spontaneous dermatitis in Mfge $8^{-/-}$female mice. ${ }^{* *} P=0.001$. (B) Left: H\&E staining of skin from 12-month-old WT or Mfge $8^{-/-}$mice with dermatitis. Right: frozen sections of skin were prepared from 12-month-old WT or Mfge $8^{-/-}$mice with dermatitis. Infiltration of CD8 $8^{+} \mathrm{T}_{\text {cells }}$ in the skin lesion was demonstrated by FITC-labeled anti-CD8 antibody. The results are representative of 6 mice examined. (C) CD11 ${ }^{+}$and CD11b+ APCs were isolated from 2- to 4-month-old $\mathrm{Mfge}^{+/-}$(control) or $\mathrm{Mfge}^{-/-} \mathrm{K}-\mathrm{mOVA}$ mice $(n=4)$ using a cocktail containing biotinylated anti-CD11c and anti-CD11b. Increasing numbers of APCs were used to stimulate $2 \times 10^{5}$ OT-I CD8 ${ }^{+} \mathrm{T}$ cells. T cell proliferation (left) and IFN- $\gamma$ production (right) were evaluated by $\left[{ }^{3} \mathrm{H}\right]$-thymidine incorporation and ELISA, respectively. ${ }^{*} P=0.01$. Results are representative of 3 experiments with 4 mice in each group. Error bars represent SD.

RIP-mOVA mice (24), we examined the urine and detected blood in the urine of all (3/3) 6-week-old $M$ fge $8^{-/-}$but not in any (0/6) agematched WT RIP-mOVA mice at 7 days after OT-I transfer, indicating more severe damage in the kidneys of the knockout mice. The accelerated destruction of islets in $\mathrm{Mfge}^{-/-}$RIP-mOVA mice by OT-I T cells was not likely to be caused by a reduced regulatory $\mathrm{T}$ cell population, since Foxp 3 expression in various lymphoid tissues was similar between WT and $\mathrm{Mfge}^{-1-}$ mice of various ages (Supplemental Figure 4).

Spontaneous dermatitis and enhanced cross-presentation of skin antigen by APCs from MFG-E8-deficient mice. The studies so far indicated that, in the absence of MFG-E8, $\mathrm{CD}^{+} \mathrm{T}$ cells are chroni- cally stimulated and that antigen-specific $\mathrm{CD}^{+} \mathrm{T}$ cells become more activated by an endogenous pseudo-self antigen in a model of type 1 diabetes. Since we observed that, as MFG-E8 mice aged, more than $50 \%$ of female mice developed spontaneous dermatitis (Figure 4A) and that $\mathrm{CD}^{+} \mathrm{T}$ cells could be detected in the skin lesions (Figure 4B), we wondered whether this phenotype was caused by enhanced cross-presentation of skinassociated antigen to self-reactive $\mathrm{CD}^{+} \mathrm{T}$ cells. To directly test this hypothesis, we crossed $M f g e 8^{-/-}$with $\mathrm{K}$-mOVA mice, which express membrane-bound OVA on keratinocytes (25). We isolated CD $11 \mathrm{c}^{+} \mathrm{CD} 11 \mathrm{~b}^{+}$APCs from the skin-draining lymph nodes from 2- to 4-month-old heterozygous (+/-) or homozygous 


\section{A}
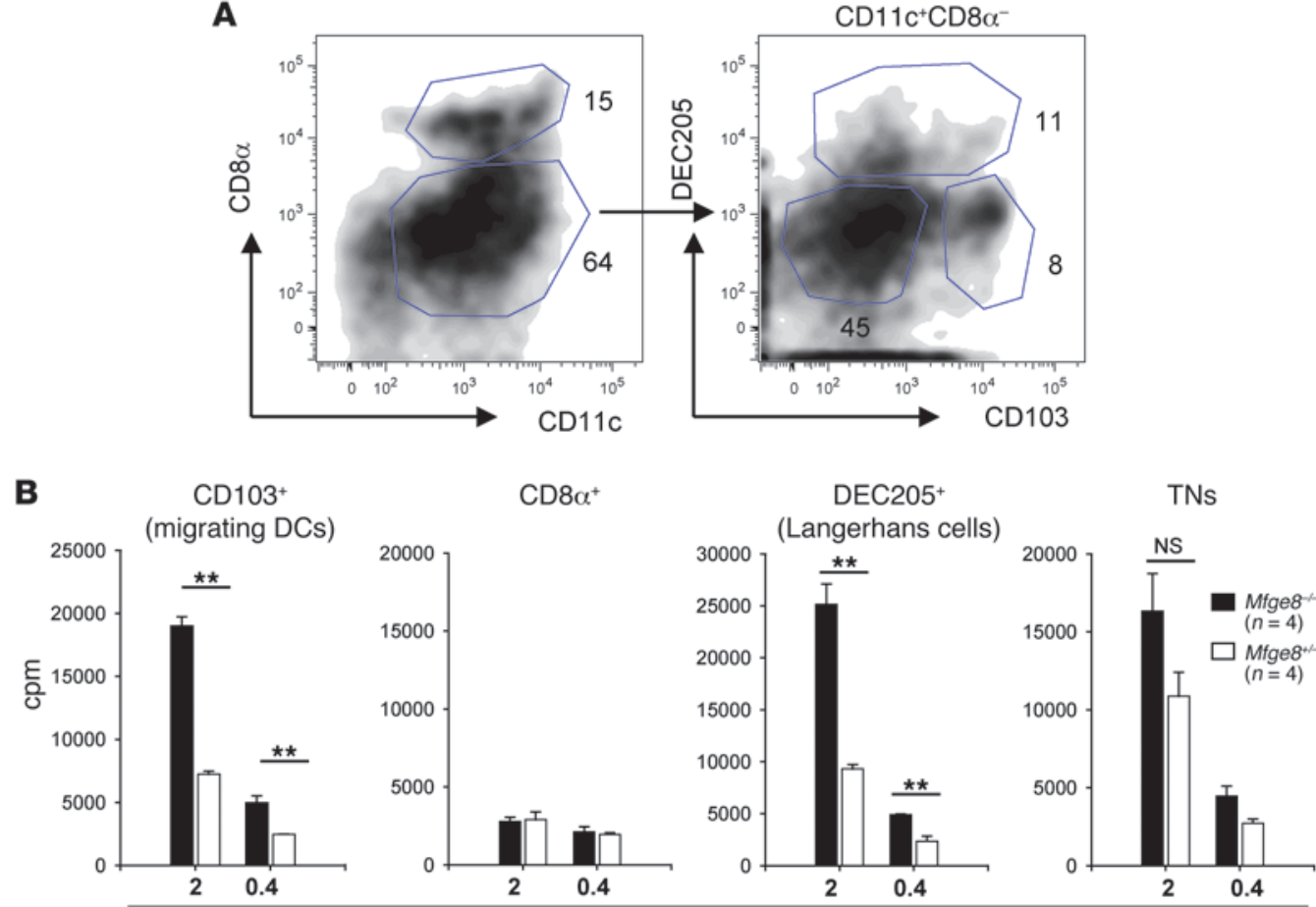

$\mathrm{APC}$ numbers $\left(\times 10^{4}\right)$

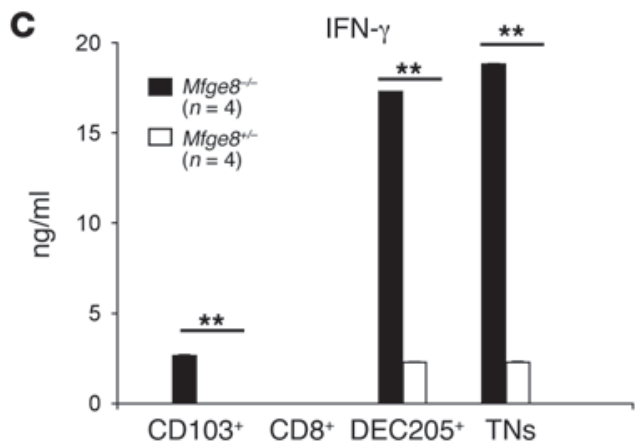

\section{Figure 5}

Langerhans cells and migrating DCs are responsible for the enhanced cross-presentation by APCs in Mfge $8^{-1-}$ K-mOVA mice. (A) APCs from either 2-month-old $\mathrm{Mfge}^{-/-} \mathrm{K}-\mathrm{mOVA}$ or age-matched $\mathrm{Mfge}^{+/-} \mathrm{K}-\mathrm{mOVA}(n=4)$ mice were first enriched by positive selection using a cocktail containing anti-CD11c and anti-CD11b antibodies. Enriched APCs were then gated according to their expression of CD11c and CD8 $\alpha$. CD11 $\mathrm{c}^{+} \mathrm{CD} 8 \alpha^{-}$cells were further separated based on their expression of DEC205 and CD103. Langerhans cells $\left(C D 11 \mathrm{c}^{+} \mathrm{CD} 8 \alpha^{-} \mathrm{DEC} 205^{+}\right)$, migrating DCs (CD11 $\left.\mathrm{c}^{+} \mathrm{CD} 8 \alpha^{-} \mathrm{CD} 103^{+}\right)$, triple negatives (TNs) (CD11 $\left.\mathrm{c}^{+} \mathrm{CD} 8 \alpha^{-} \mathrm{DEC} 205^{-} \mathrm{CD} 103^{-}\right)$. The numbers in the dot plots denote the percentages of each population. (B) $2 \times 10^{4}$ or $0.4 \times 10^{4}$ sorted APCs were mixed with $5 \times 10^{5} \mathrm{OT}-\mathrm{I}$ CD8 ${ }^{+} \mathrm{T}$ cells. T cell proliferation was assessed by $\left[{ }^{3} \mathrm{H}\right]$-thymidine incorporation. Triple negatives (CD11 $\left.\mathrm{C}^{+} \mathrm{CD} 8 \alpha^{-} \mathrm{CD} 103^{-} \mathrm{DEC} 205^{-}\right)$. (C) The level of IFN- $\gamma$ in the supernatant was evaluated by ELISA. Only OT-I T cells stimulated with $2 \times 10^{4}$ APCs produced detectable levels of IFN- $\gamma$. ${ }^{* \star} P<0.01$. The results from A-C are representative of 3 independent experiments. Error bars represent SD.

MFG-E8 K-mOVA (-/-) mice using anti-CD11c and anti-CD11b cocktail, and stimulated OT-I T cells with increasing numbers of APCs. As shown in Figure 4C, APCs recovered from MFGE8-deficient mice were more efficient than those from the control group in stimulating OT-I T cells. Further fractionation of APCs from 2-month-old mice by sorting demonstrated that migrating DCs $\left(\mathrm{CD} 11 \mathrm{c}^{+} \mathrm{CD} 8 \alpha^{-} \mathrm{CD} 103^{+}\right)$and Langerhans cells $\left(\mathrm{CD} 11 \mathrm{c}^{+} \mathrm{CD} 8 \alpha^{-} \mathrm{DEC} 205^{+}\right)$were the primary APCs responsible for the enhanced cross-presentation in $\mathrm{Mfge}^{-/-}$mice (Figure 5). This is consistent with the recent observation made by Bedoui et al. (26). Interestingly, despite the small difference in their abilities to induce OT-I T cell proliferation, triple-negative DCs (CD8 $\alpha^{-}$DEC205-CD103-) in the LNs from $M$ fge $8^{-/-}$mice contributed to the increased IFN- $\gamma$ production as well, suggesting MFG-E8 deficiency might also enhance the cross-presentation by some DEC205-CD $103^{-}$migrating DCs (27). The higher efficiency of cross-presentation by APCs was not explained by increased expression of known costimulatory molecules, as there were no significant differences between the levels of expression of CD86, CD80, PDL-1, PDL-2, or ICOSL on APCs 
A

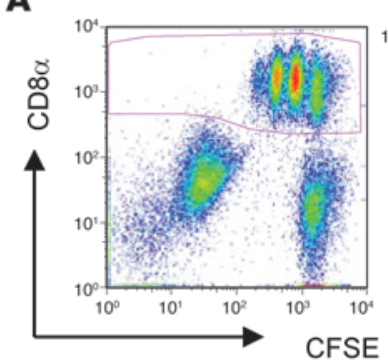

Division index:
Total DC/T 1:1

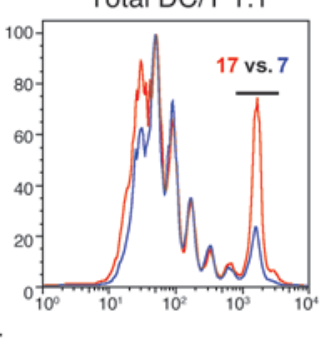

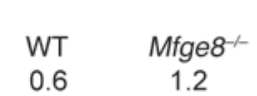
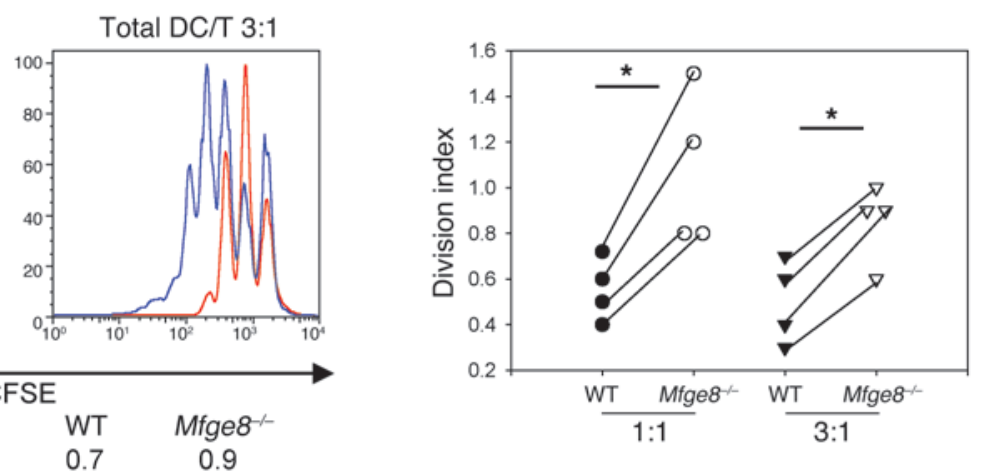

C
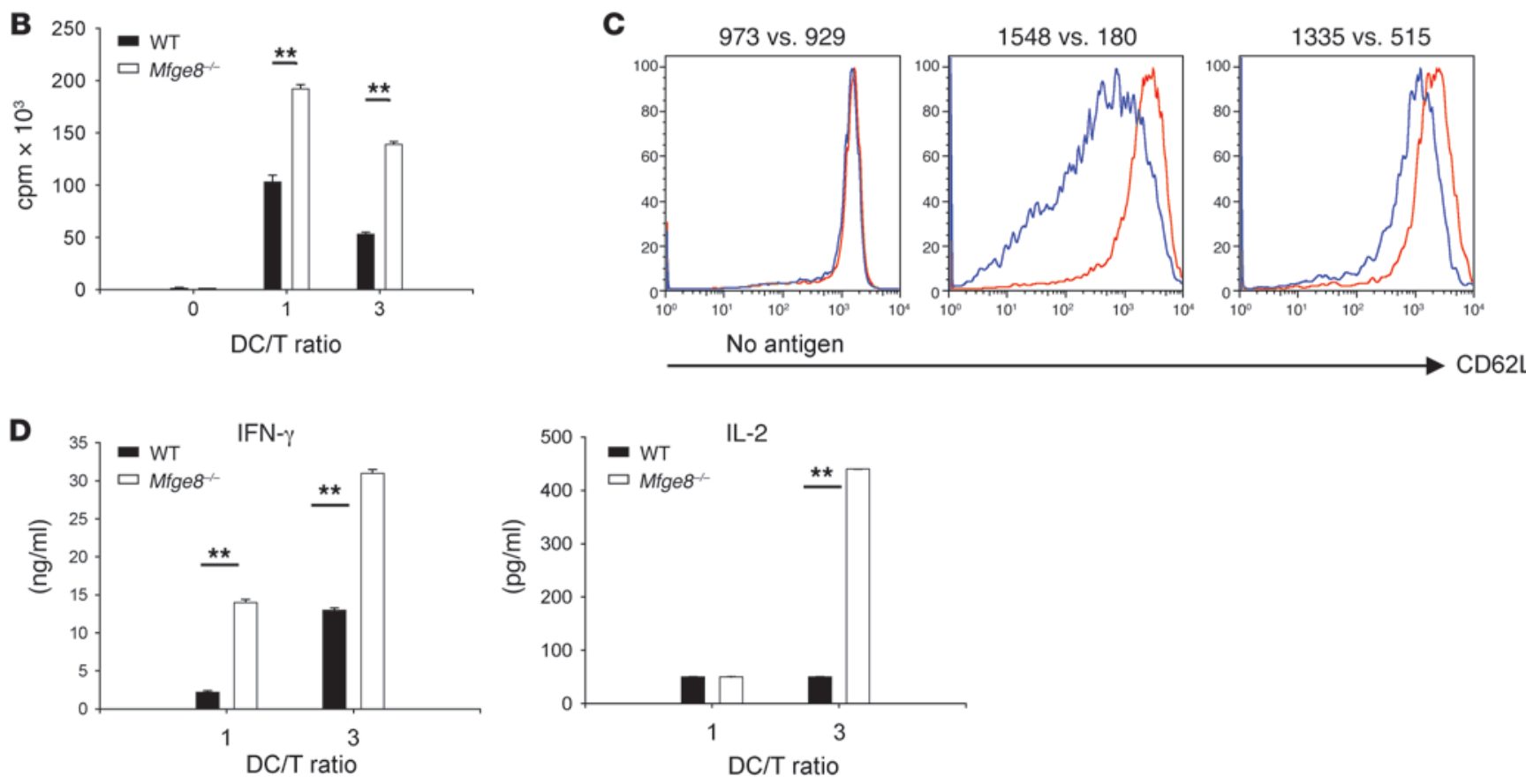

\section{Figure 6}

MFG-E8 deficiency enhances cross-presentation of apoptotic cell-associated antigen by BMDCs. (A) Right: day-6 immature BMDCs from 2-month-old $\mathrm{Mfge}^{-1-}$ or WT mice were incubated with Apo-OVA for 24-36 hours. Total immature DCs were collected and used to stimulate $5 \times 10^{5}$ CFSE-labeled OT-I T cells at either a 1:1 or 3:1 ratio for 3 days. OT-I T cells were gated (left panel) and their proliferation analyzed by flow cytometry (histogram: red, WT; blue, Mfge8 ${ }^{-1-}$ BMDCs). The division indices were quantified by FlowJo software. The percentages of undivided cells at DC/T ratio $1: 1$ were shown at the top. Right: division indices of 4 independent experiments. ${ }^{*} P=0.01$ (paired $t$ test). (B) The proliferation of OT-I T cells was also quantified using $\left[{ }^{3} \mathrm{H}\right]$-thymidine incorporation in independent experiments ${ }^{* *} P<0.01$. The result is representative of 3 experiments with similar results. (C) Left: OT-I T cells were stimulated with DCs containing apoptotic cells without OVA. Middle: OT-I T cells were stimulated with total DC/T ratio 3:1 as in A. At day 3, CD62L expression on OT-I T cells was analyzed by flow cytometry. Right: to disrupt $\mathrm{DC} / \mathrm{T}$ cell interaction, cells were vigorously pipetted at day 2. The expression of CD62L on OT-I T cells was analyzed at day 3 (histogram: red, WT; blue, Mfge $8^{--}$BMDCs). The MFIs (WT versus Mfge $^{-/-}$) are shown above. (D) Concentrations of IFN- $\gamma$ and IL-2 from day-3 supernatants were analyzed by ELISA. ${ }^{* *} P<0.01$. The results are representative of 3 experiments with similar results. Error bars represent SD.

obtained from skin-draining LNs from 1-year-old WT, $M f g e 8^{-/-}$, or $M$ fge $8^{-/-}$mice with mild dermatitis (Supplemental Figure 5). Neither did we find a significant change of either CD $11 c^{+}$or $\mathrm{CD}_{1} 1 \mathrm{~b}^{+} \mathrm{APC}$ cell numbers nor upregulation of costimulatory molecules in the spleens of 1 -year-old $\mathrm{Mfge}^{-/-}$mice (Supplemental Figure 6). Furthermore, we did not detect any increase of inflammatory cytokines such as IL-12 or TNF- $\alpha$ in the spleens of 4- to 5-month-old $\mathrm{Mfge}^{-/-}$mice by mRNA array expression analysis (Supplemental Figure 7).
Enhanced cross-presentation of apoptotic cell antigen can be modeled in in vitro-derived DCs. To dissect how MFG-E8 affects the cross-presentation of apoptotic cells, we next established an in vitro system in which a homogenous source of APCs is amenable to examination. Immature BM-derived dendritic cells (BMDCs) produce significant amounts of MFG-E8 (28) and are able to cross-present apoptotic cell-associated antigen without further maturation (see below). We loaded day- 6 immature BMDCs with Apo-OVA and used them to stimulate OT-I T cells at total DC/T ratios of 1:1 and 3:1. 

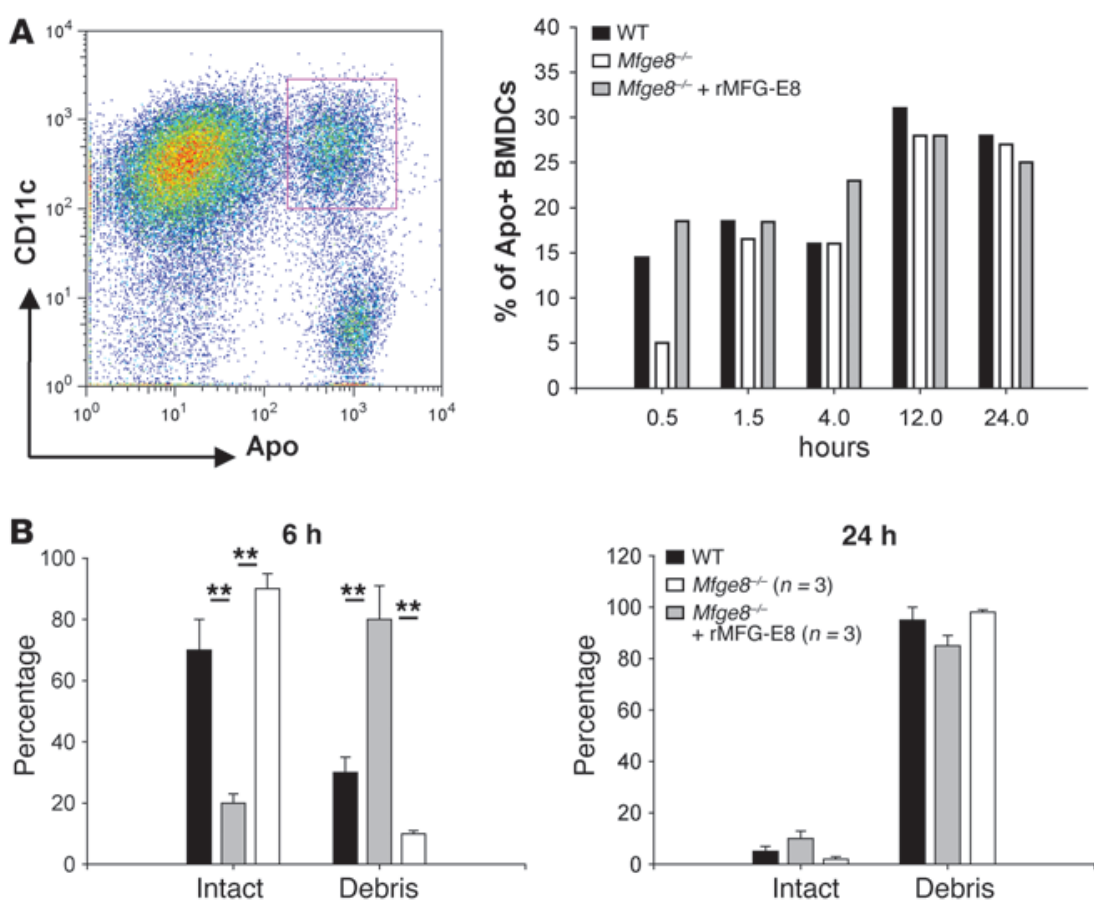

\section{Figure 7}

MFG-E8 deficiency leads to defective uptake of intact apoptotic cells and a concomitant increase of cell debris in DCs. (A) Apoptotic cells were labeled with PKH67 (green) and incubated with day-6 immature BMDCs from 2-month-old WT or $\mathrm{Mfge}^{-/-}$mice. To correct MFG-E8 deficiency, recombinant MFG-E8 (rMFG-E8) $(0.25 \mu \mathrm{g} / \mathrm{ml})$ was added back to $\mathrm{Mfge}^{-/-} \mathrm{BMDCs}$. The dot plot in the left panel shows the gate for quantification. The percentage of $\mathrm{CD} 11 \mathrm{c}^{+}$cells from each group that contained apoptotic cells was quantified by flow cytometry, and the results are summarized in the right panel. Results are representative of 3 experiments. (B) Ingested PKH-positive material was designated as intact apoptotic cells or cell debris based on size and appearance (see below). The percentage of each type was compared following analysis of at least 15 individual BMDCs obtained from WT and $\mathrm{Mfge}^{-/-}$mice at 6 and 24 hours after incubation. The results (mean $\pm S D$ ) from at least 3 experiments are shown. ${ }^{\star \star} P<0.01$.
Adding Apo-OVA to immature BMDCs did not cause their maturation (Supplemental Figure 8). The relative proportion of DCs used was higher than that for foreign antigens but may reflect physiological conditions in vivo for the following reasons: (a) assuming constant uptake of dying cells in vivo (5), the number of self antigen-containing APCs is likely to exceed the number of antigen-specific T cells (estimated to be 1,000-10,000 per mouse (29); (b) only $30 \%$ of BMDCs phagocytosed apoptotic cells (see below); (c) a small number of DCs contained processed OVAp/MHCI complex; and (d) immature DCs are relatively inefficient in presenting antigen. Consistent with the in vivo observations, higher numbers of OT-I T cells stimulated with DCs derived from $M \mathrm{fge}^{8^{-/-}}$mice underwent cell proliferation, displayed lower levels of CD62L, and produced more IL- 2 and IFN- $\gamma$ than those stimulated with WT BMDCs (Figure 6). In Mfge $8^{-1-}$ DC cultures, the increased downregulation of CD62L required close interaction between OT-I T cells and DCs, since disrupting their interactions by vigorous pipetting restored CD62L on OT-I T cells (Figure 6C). In contrast to apoptotic cells, BMDCs from WT and mutant strains did not differ in their ability to present either the OVA peptide or soluble OVA (see below), arguing that the increased responses to Apo-OVA were not due to differences in costimulatory molecule expression and that the enhanced processing of exogenous antigen was specific to apoptotic cells. Furthermore, we did not observe any difference in BMDC expression of inflammatory cytokines or CD86 in response to LPS stimulation between the 2 strains (data not shown).

MFG-E8 deficiency leads to accumulation of apoptotic cell debris outside oflysosomes. Endocytosed particles (e.g., viral, microbial, apoptotic cells) are rapidly digested in macrophages through phagosomelysosome maturation (30). The superiority of DCs in presenting antigen can be partly attributed to their ability to store antigen longer than macrophages (15). The routes of antigen processing inside the APCs also affect the MHCI and MHCII epitopes presented on the cell surface (31). In macrophages and DCs, phago- somes that contain apoptotic cells fuse with lysosomes shortly after ingestion $(30,32)$. Since MFG-E8 mediates phagocytosis through the integrins $\alpha_{v} \beta_{5}$ and $\alpha_{v} \beta_{3}$ and integrins are closely linked to phagosome maturation (33), we considered whether MFG-E8 deficiency would alter the processing of apoptotic cells inside DCs. We labeled apoptotic cells with a lipid dye, incubated them with day- 6 BMDCs. and examined apoptotic cell-containing DCs at intervals from 30 minutes to 24 hours by flow cytometry and immunofluorescence microscopy. As shown in Figure 7A, Mfge $\mathrm{8}^{-/-}$BMDCs were less efficient than WT cells in the uptake of apoptotic cells in the first 30 minutes, which is consistent with published results (28). However, the percentage of DCs that contained apoptotic material was no longer different after the first hour. Significantly, recombinant MFG-E8 corrected the early deficiency of apoptotic cell uptake by $M f g e 8^{-/-}$BMDCs, indicating that differences were not explained by possible secondary changes in DC maturation in $M f^{g} \mathrm{~S}^{-/-}$mice.

To more carefully determine whether there were differences in the processing of apoptotic material between DCs obtained from WT and MFG-E8-deficient mice, we used immunofluorescence microscopy. We labeled apoptotic cell membranes with a lipid dye (PKH67) and examined cells under conventional wide-field microscopy. Consistent with the role of MFG-E8 in facilitating apoptotic cell removal, intact apoptotic cells (which often appeared as ring-like structures; see below) were observed in WT BMDCs, but rarely in $M f g e 8^{-1-}$ BMDCs, at early time points. In addition to intact apoptotic cells, we also detected smaller cell fragments that were smaller and more condensed inside DCs. While cell debris were infrequent in WT BMDCs, they were the usual findings in $\mathrm{Mfge}^{-/-}$DCs (Figure 7B). In agreement with the original report (28), adding recombinant MFG-E8 $(0.25 \mu \mathrm{g} / \mathrm{ml})$ to Mfge $8^{-/}$BMDCs restored the uptake of intact apoptotic cells (see below). Both intact apoptotic cell and debris were colocalized with MHC I, regardless of the expression of MFG-E8 (data not shown). 
A

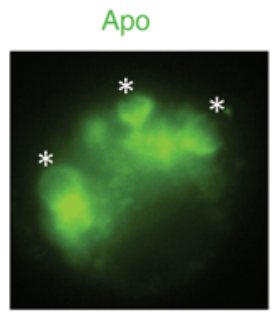

LysoTracker
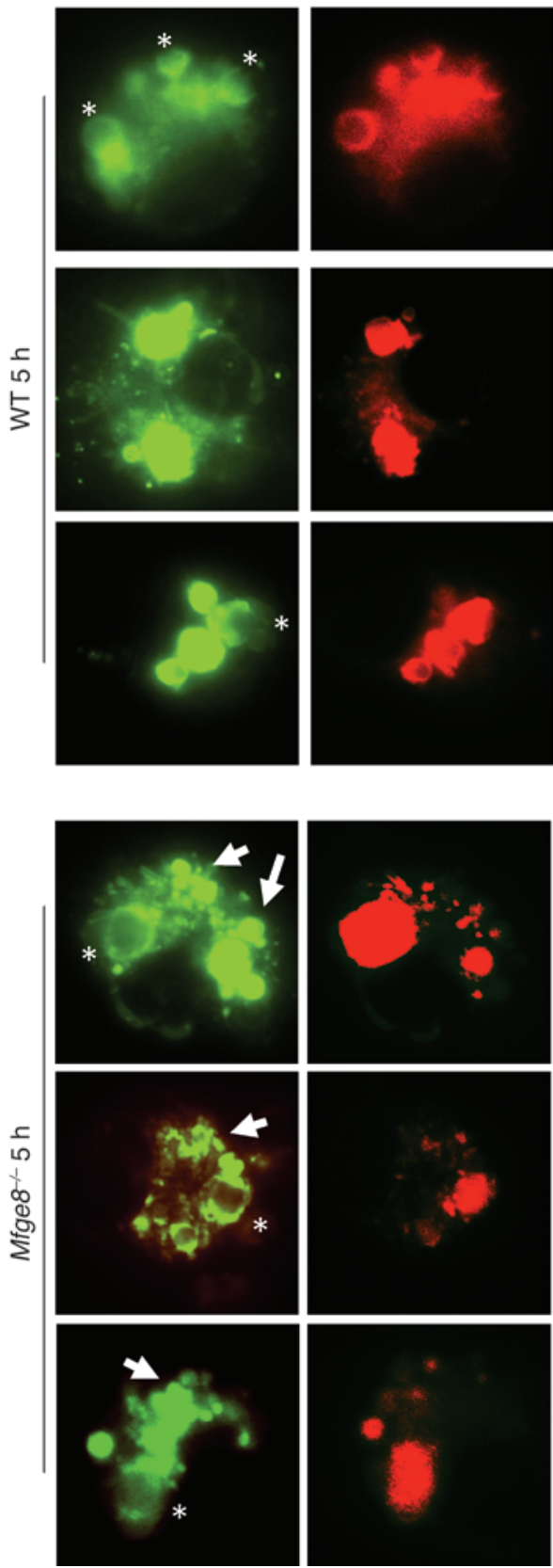
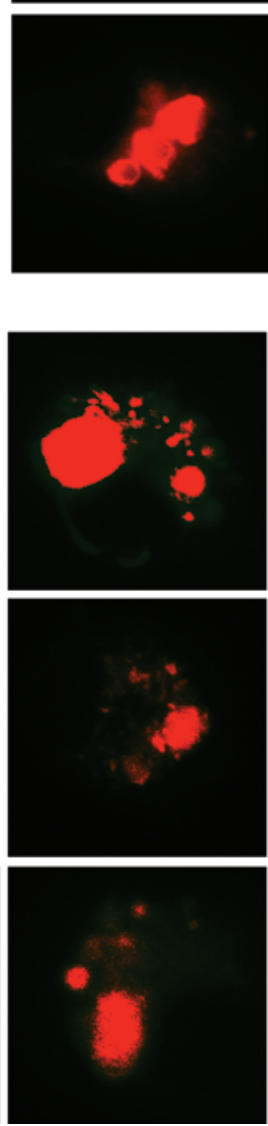

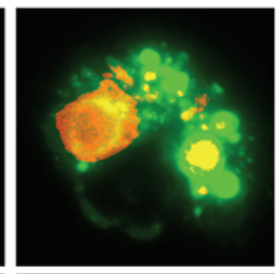

Merge
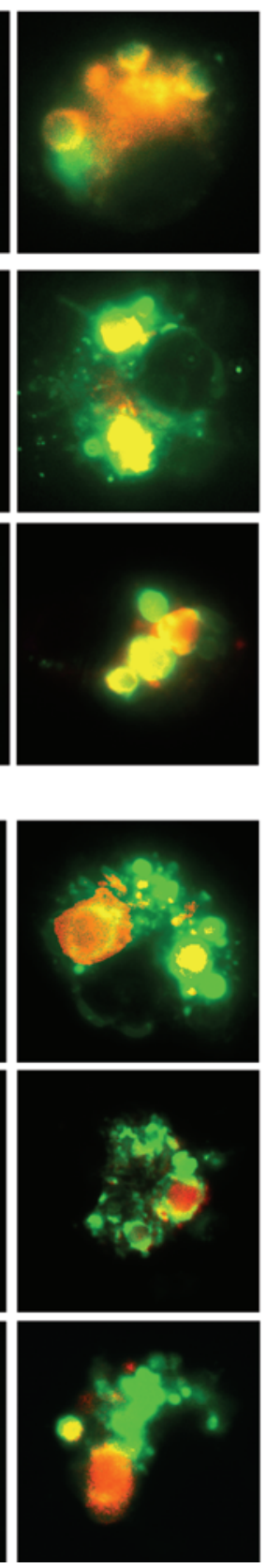

B

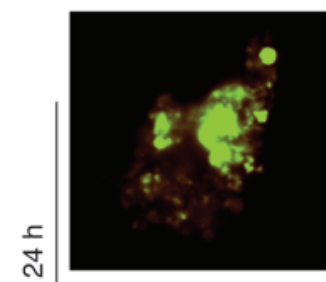

芕
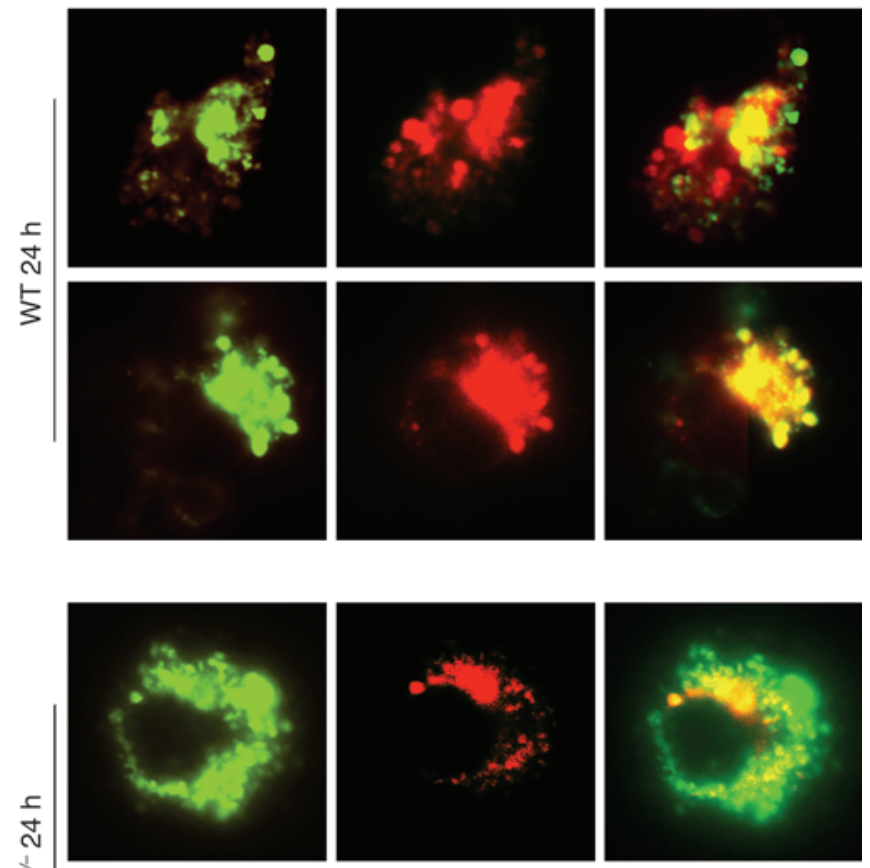

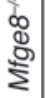
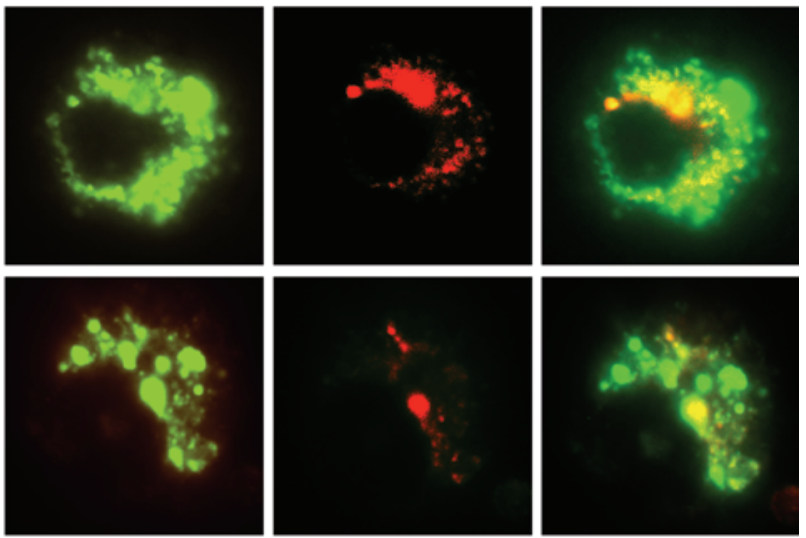

\section{Figure 8}

Reduced acidification of apoptotic cell debris in unfixed $\mathrm{Mfge8}^{-/-} \mathrm{DCs}$. Day-6 immature BMDCs from either WT or $\mathrm{Mfge}^{-1-}$ mice were labeled with LysoTracker (red). 30 minutes later, PKH67-labeled apoptotic cells (green) were added to DCs at a 5:1 ratio. LysoTracker-containing medium was replaced at 2 hours. DCs were collected at 5 and 24 hours after incubation. After adhering to glass slides, the acidification of apoptotic cell materials was examined using wide-field microscopy without fixation. Intact apoptotic cells are seen as ring-like structures (asterisks). (A and B) BMDCs from either WT or $\mathrm{Mfge}^{-/-}$mice were labeled with LysoTracker (red) and examined under wide-field microscope at 5 hours (A) and 24 hours (B) after incubation with apoptotic cells. Unlike intact apoptotic cell (asterisk), smaller cell debris were clustered, smaller, and brighter (arrow). Representative cells are shown for each group. Original magnification, $\times 400$.

acidified and intensively labeled with LysoTracker (Figure 8B). The intensive labeling of apoptotic cells required phagocytosis, since apoptotic cells outside BMDCs remained LysoTracker negative (Supplemental Figure 9B). Consistent with the role of MFG-E8 in facilitating apoptotic cell uptake, MFG-E8-deficient BMDCs contained on average only $0-1$ intact large apoptotic cells, but those intact apoptotic cells appeared to acidify with kinetics similar to that observed in WT BMDCs. In contrast to WT BMDCs, we also observed an increase of smaller, brighter, denser apoptotic cell fragments within $\mathrm{Mfge}^{-/-}$BMDCs (Figure 8A). Of note, unlike intact apoptotic cells within the same DCs, most of the cell debris were not stained with LysoTracker. At 24 hours after ingestion, apoptotic material within WT BMDCs, presumably the digested products 
A
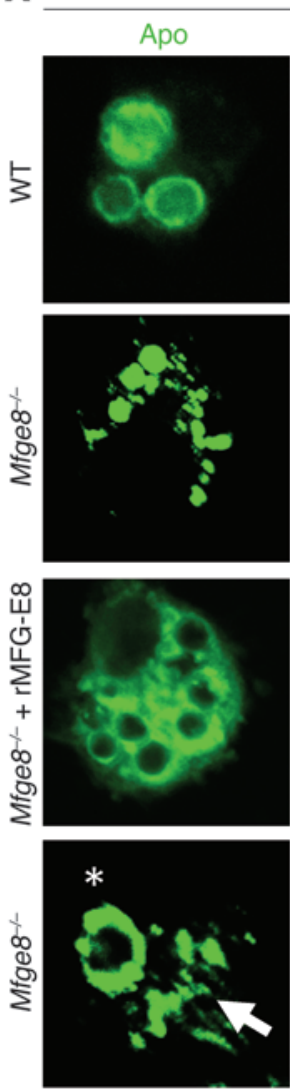

$6 \mathrm{~h}$
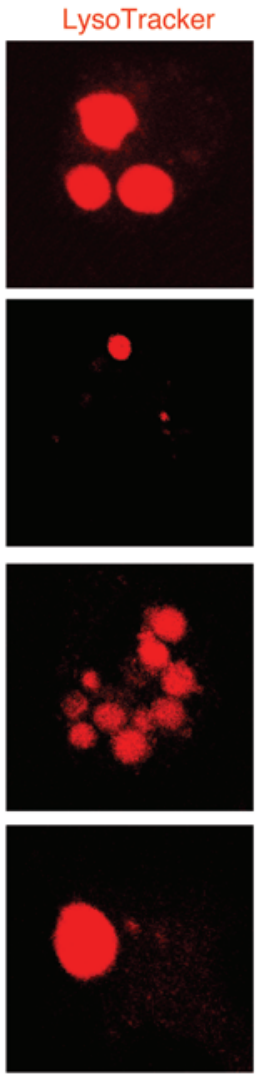

$24 \mathrm{~h}$
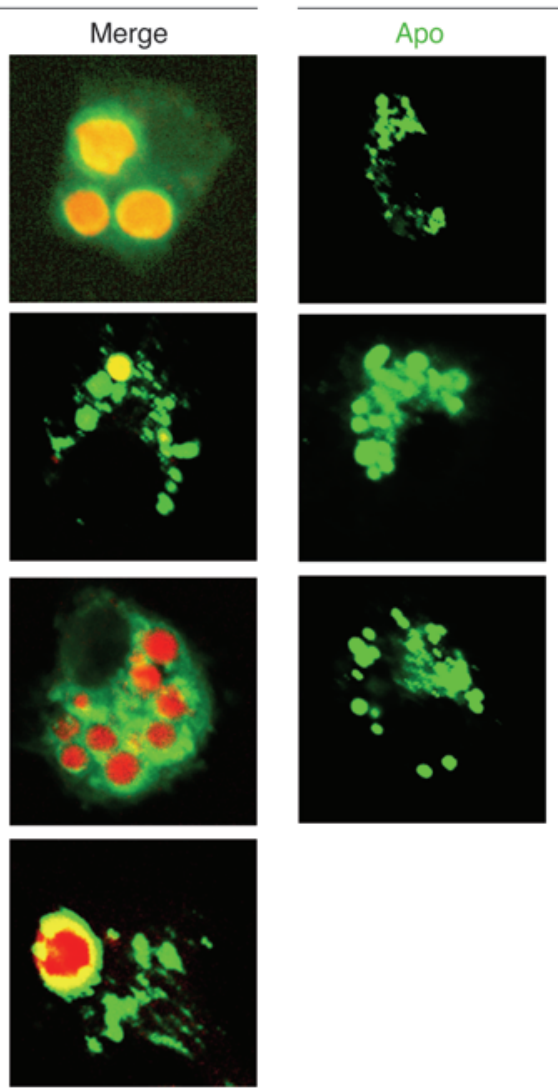
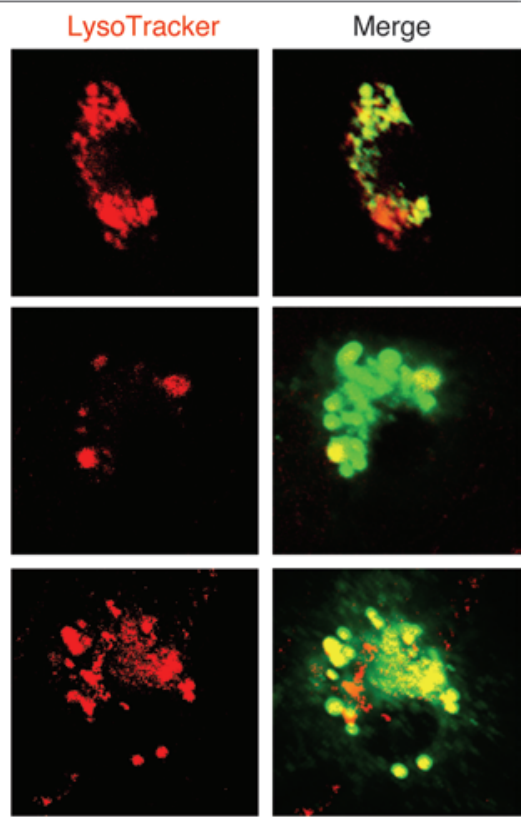

B
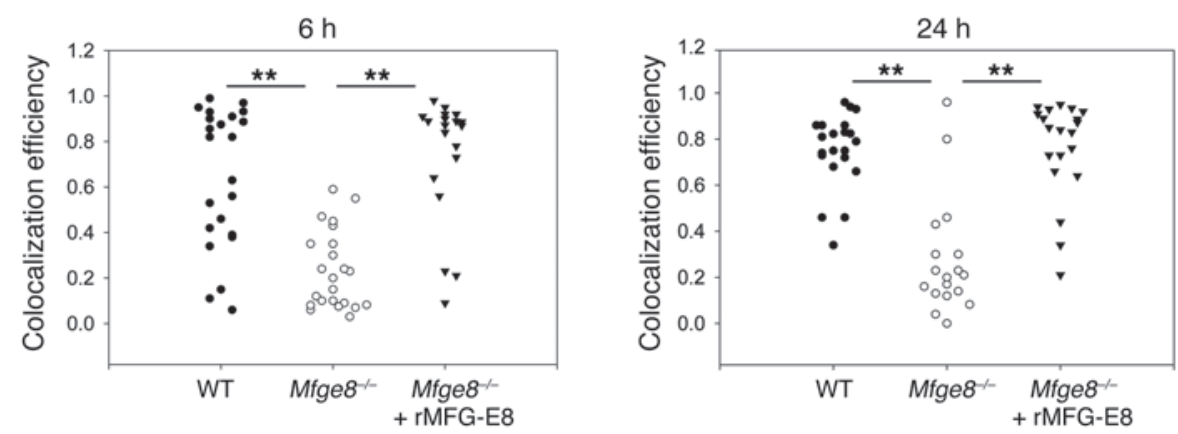

Figure 9

Visualization of reduced acidification of apoptotic cell debris in fixed Mfge8 ${ }^{-/-}$DCs by confocal microscopy. (A) Day-6 immature BMDCs from either WT or $\mathrm{Mfge}^{-/-}$mice were labeled with LysoTracker (red) as in Figure 8. DCs were fixed with $4 \%$ PFA and examined under confocal microscope at 6 hours (left) and 24 hours (right) after incubation with apoptotic cells. To correct MFG-E8 deficiency, recombinant MFG-E8 $(0.25 \mu \mathrm{g} / \mathrm{ml})$ was mixed with apoptotic cells before adding to the BMDCs. Intact apoptotic cells (asterisk); smaller cell debris (arrow). At 6 hours, in a few Mfge $8^{-/}$BMDCs, both intact apoptotic cell and cell debris could be found within the same cell (bottom panel). Experiments were analyzed using Leica SP1 confocal microscope. Original magnification, $\times 400$. (B) Colocalization of LysoTracker with all apoptotic cell material (intact or cell debris) in WT, Mfge $8^{-/-}$,or $\mathrm{Mfge}^{-/-}$plus rMFG-E8 BMDCs at 6 and 24 hours after ingestion. Results are representative of 3 experiments. ${ }^{* \star} P<0.001$.

from intact apoptotic cells, remained highly acidic (Figure 8B). In contrast, most apoptotic material within $\mathrm{Mfge}^{-/-}$BMDCs was not acidic, suggesting that phagosomes containing debris did not undergo acidification even after 24 hours (Figure 8B).

To better distinguish intact apoptotic cells and smaller cell debris after apoptotic cell ingestion, BMDCs were fixed and examined by confocal microscopy. Despite a reduction in LysoTracker intensity by fixation, signals from a single optical plane collected by confocal microscopy allowed us to clearly distinguish intact apoptotic cells from smaller cell debris by their ring-like structure and central DAPI staining (Figure 9A and see below). Similar to the results from wide-field microscopy, at 24 hours, the intact apoptotic cells within WT BMDCs were no longer detectable, but partially digested cell debris were observed within acidic compartments (Figure 9A). In contrast, most cell debris in $\mathrm{Mfge}^{-/-}$DCs remained LysoTracker negative 
A
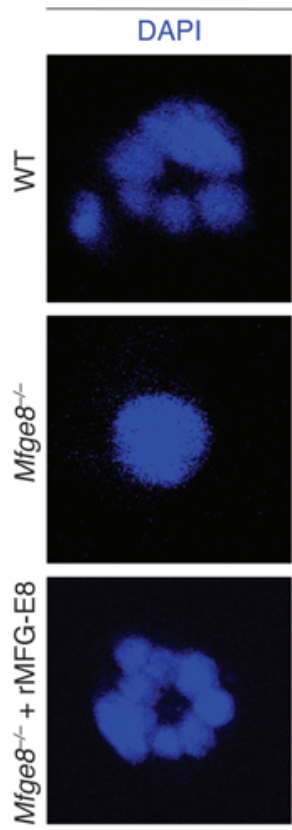

B
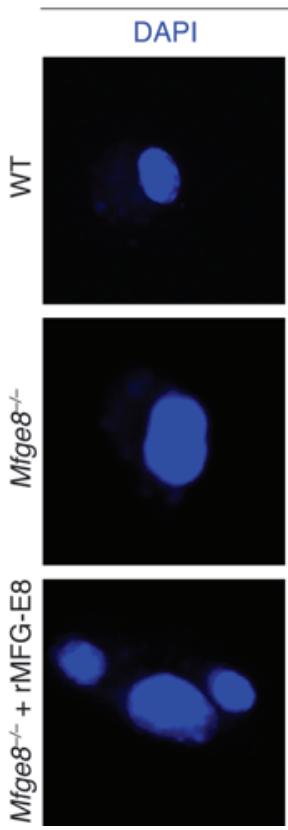

$6 \mathrm{~h}$
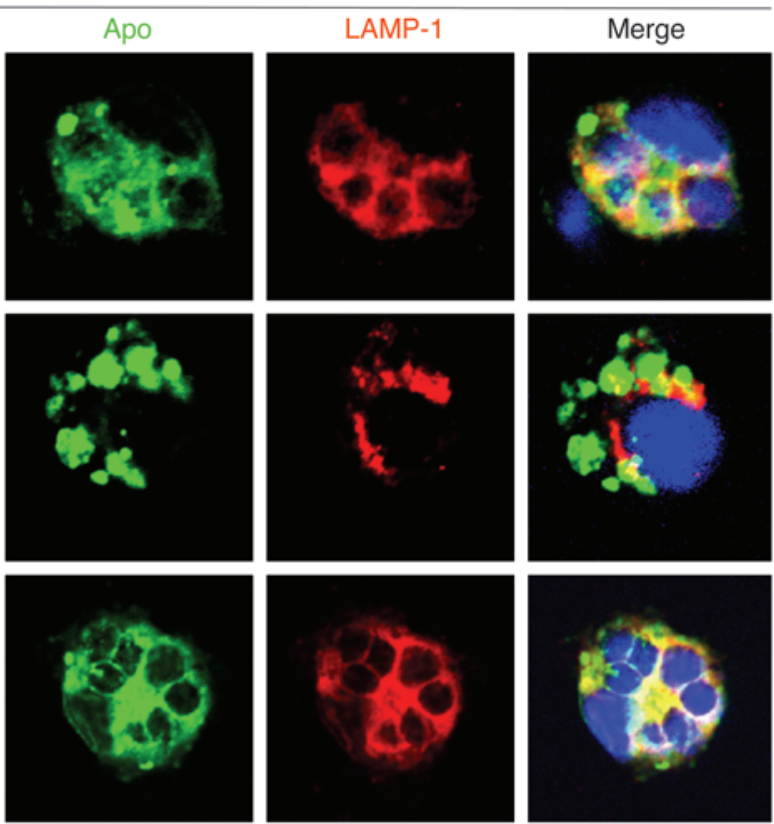

$24 \mathrm{~h}$
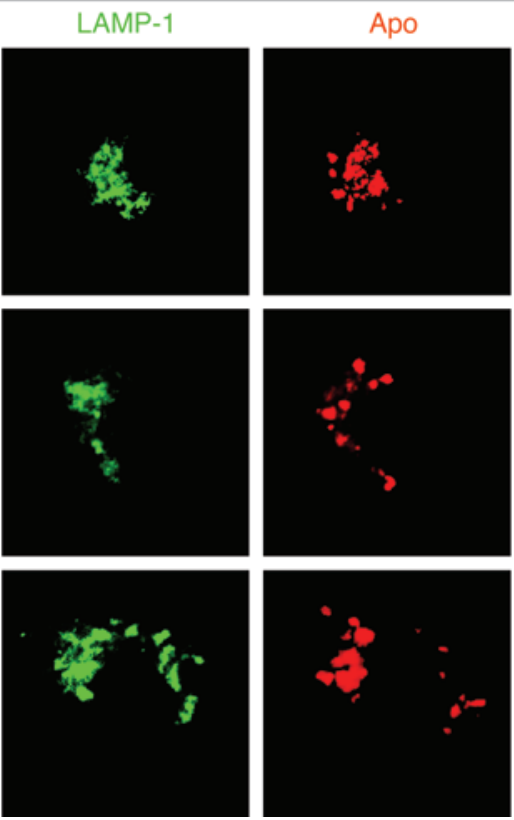

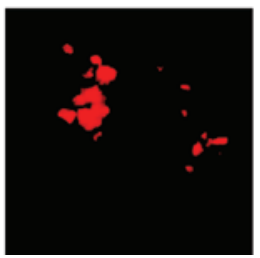

C
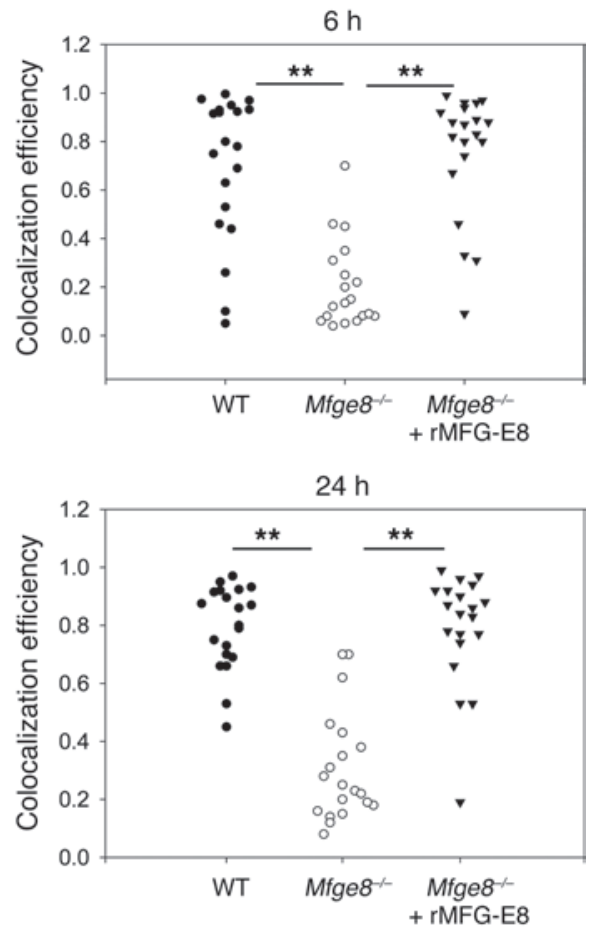

Figure 10

Phagosomes containing apoptotic cell fragments fail to mature in DCs from MFG-E8-deficient mice. (A) Upper left: PKH67-labeled (green) apoptotic cells were incubated with BMDCS as in Figure 8A for 6 hours. Cells were fixed and permeabilized; LAMP-1positive compartments were visualized by biotinylated anti-LAMP-1 and Alexa Fluor 555-labeled streptavidin. To correct MFG-E8 deficiency, recombinant MFGE8 $(0.25 \mu \mathrm{g} / \mathrm{ml})$ was mixed with apoptotic cells before adding to the BMDCs. Similar results were observed when apoptotic cells were labeled with PKH27 (red) and LAMP-1 was visualized by Alexa Fluor 488labeled streptavidin (not shown). Experiments with DAPI staining were analyzed using Zeiss 510 Meta confocal microscope. Original magnification, $\times 400$. (B) PKH27-labeled (red) apoptotic cells were incubated with BMDCs for 24 hours; localization of apoptotic cells was visualized by anti-LAMP-1 antibody. (C) Colocalization of LAMP-1 with all apoptotic cell material in WT, $\mathrm{Mfge}^{-1-}$, or $\mathrm{Mfge}^{-/-}$plus rMFG-E8 BMDCs at 6 and 24 hours after ingestion. Results are representative of 3 experiments. ${ }^{* *} P<0.001$.
(Figure 9A). When colocalization was quantified, a statistically significant difference between LysoTracker/apoptotic material colocalization was observed between WT and MFG-E8-deficient DCs (Figure 9B). The failure of phagosomes containing debris to become acidic at 6 hours cannot be attributed to a differentiation defect of $M \mathrm{fge}^{8^{-/}}$BMDCs, since adding recombinant MFG-E8 to $M f g e 8^{-/-}$BMDCs restored the uptake and acidification of intact apoptotic cells (Figure 9A). Also, MFG-E8 DCs were capable of acidifying the rare intact apoptotic cell ingested, as even within the same cell, the intact apoptotic was acidified whereas cell debris was not (Figure 9A).
Since LysoTracker can label both late endosomes and lysosomes $(34,35)$, we next asked whether differences in phagosome maturation could be observed in DCs obtained from WT and MFG-E8 mice. When the lysosomal marker LAMP-1 was used to detect lysosomes, LAMP-1 encircled intact apoptotic cells within WT DCs at 6 hours and was colocalized with digested debris at 24 hours after ingestion (Figure 10A). Consistent with results from LysoTracker, smaller cell debris in $\mathrm{Mfge}^{-/-}$DCs did not fuse with lysosome even after 24 hours (Figure 10B). However, the few intact apoptotic cells observed in $M \mathrm{fge}^{-/-}$DCs did become LAMP-1 positive after 2 hours, suggesting that MFG-E8 itself 
A
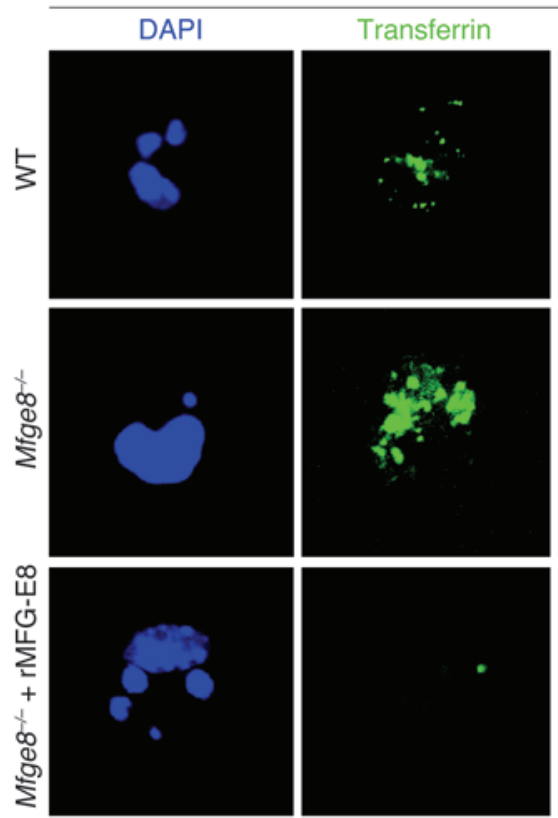

$6 \mathrm{~h}$
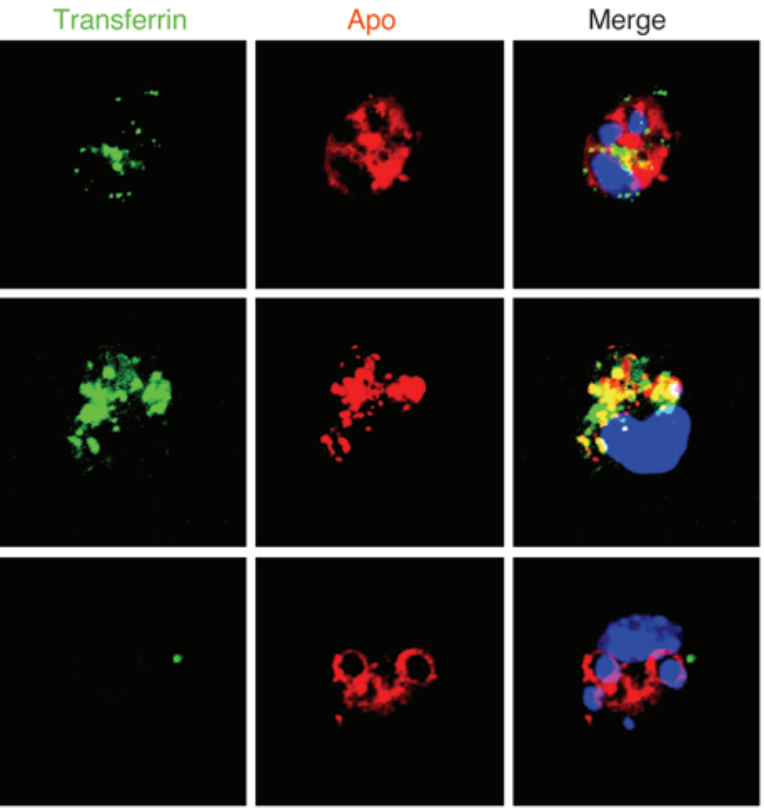

B
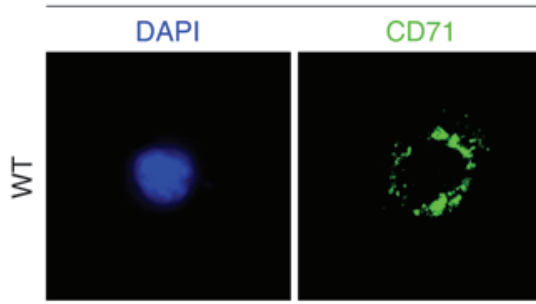

$24 \mathrm{~h}$
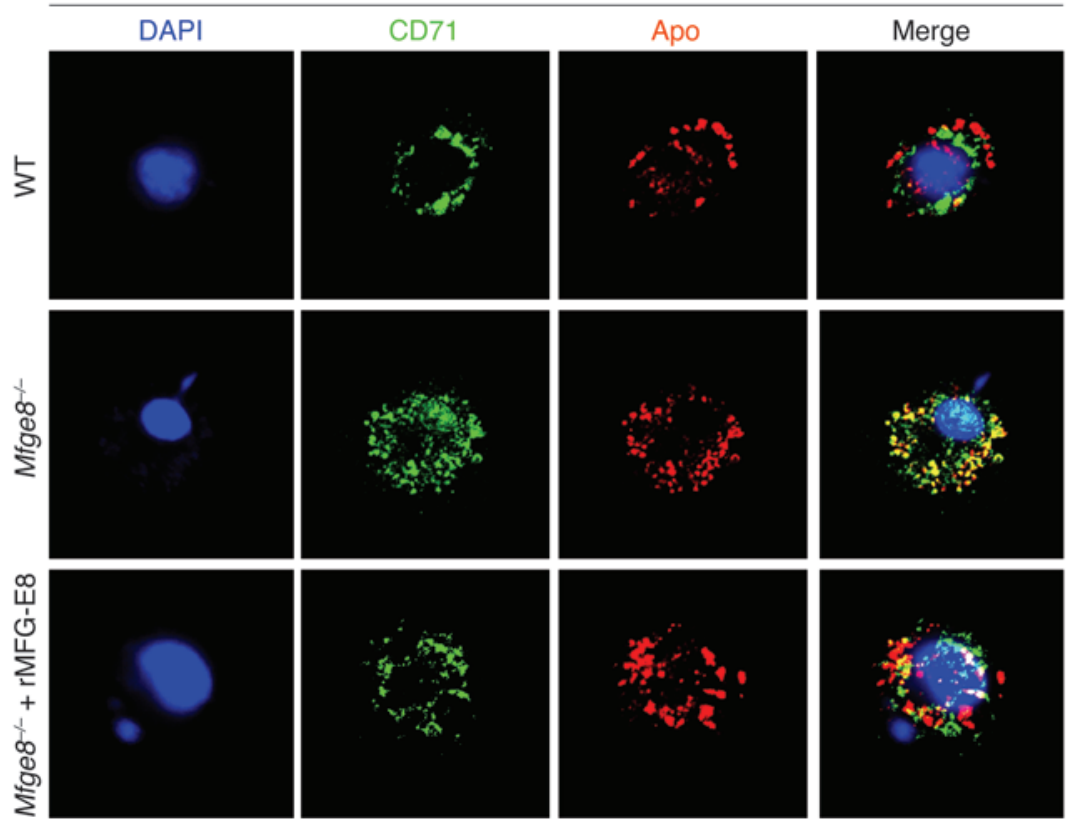

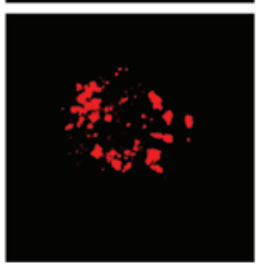

C
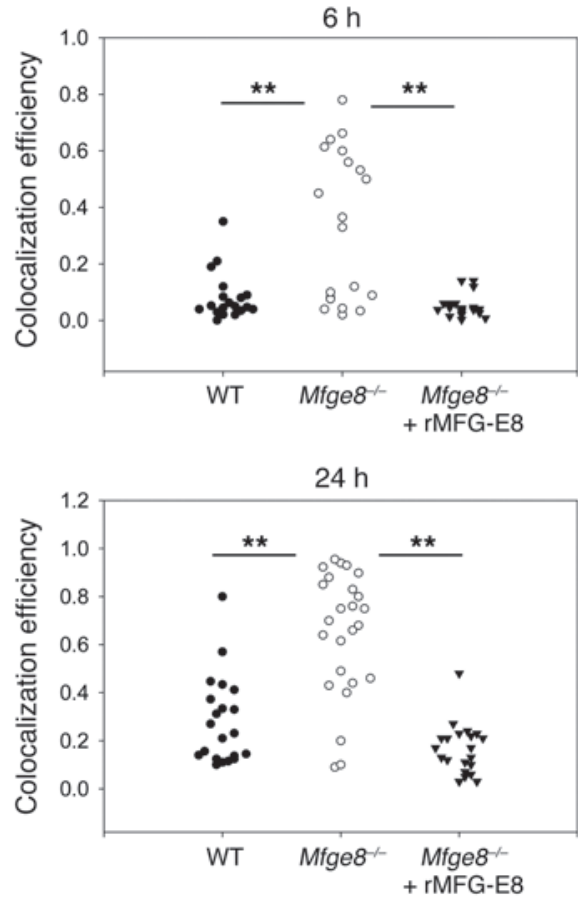

Figure 11

Apoptotic cell fragments in $\mathrm{Mfge}^{-/-}$DCs persist in transferrin-positive endosomes. (A) PKH27labeled apoptotic cells (red) were incubated with day- 6 immature BMDCS in serum-free medium supplemented with Alexa Fluor 488-labeled transferrin for 6 hours. The colocalization of transferrin and apoptotic cells was visualized by confocal microscopy. (B) PKH27-labeled apoptotic cells (red) were incubated with BMDCs for 24 hours. The colocalization of apoptotic cells and transferrin receptor (CD71) was visualized by biotinylated anti-CD71 and Alexa Fluor 488-conjugated streptavidin. Original magnification, $\times 400$. (C) Colocalization of transferrin (top) or CD71 (bottom) with all apoptotic cell material (intact or cell debris) in WT, Mfge $^{-/-}$, or Mfge $^{-/-}$plus rMFG-E8 BMDCs at 6 and 24 hours after ingestion. The results are representative of 3 experiments. ${ }^{* *} P<0.001$. was not an absolute requirement for the maturation of apoptotic cell-containing phagosome (Supplemental Figure 9C). When colocalization was quantified, a statistically significant difference between LAMP-1/apoptotic material colocalization was observed between WT and MFG-E8-deficient DCs (Figure 10C).

After phagocytosis, apoptotic cell-containing phagosomes interact sequentially with early endosomes, late endosomes, and lysosomes $(7,34)$. To further determine whether cell debris within $M f g e 8^{-/-}$DCs were processed differently, we first incubated apoptotic cells with DCs in the presence of Alexa Fluor 488 transferrin in serum-free medium for 6 hours (36). As shown in Figure 11A, although WT BMDCs containing intact apoptotic cells were very inefficient in the uptake of transferrin, more than $60 \%$ of cell debris were located in transferrin-positive compartments in $M$ fge $^{-/-}$DCs. The accumulation in transferrin ${ }^{+}$ endosomes could be reversed by adding recombinant MFG-E8 $(0.25 \mu \mathrm{g} / \mathrm{ml})$ to $M \mathrm{fge}^{-/-}$BMDC culture. Since DCs did not survive well in serum-free medium overnight, we further evaluated the subcellular location of apoptotic cell material at 24 hours with the antibody to CD71, the transferrin receptor. As shown in Figure 11B, whereas the majority of digested cell debris in WT DCs were negative for transferrin receptor, most cell debris in Mfge $8^{-/-}$DCs were colocalized with CD71. Since transferrin and transferrin receptor are localized in both sorting and recycling 
A
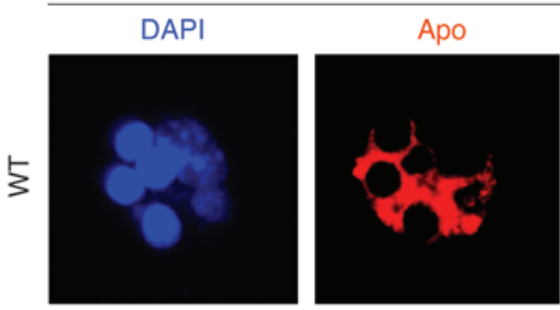

$6 \mathrm{~h}$
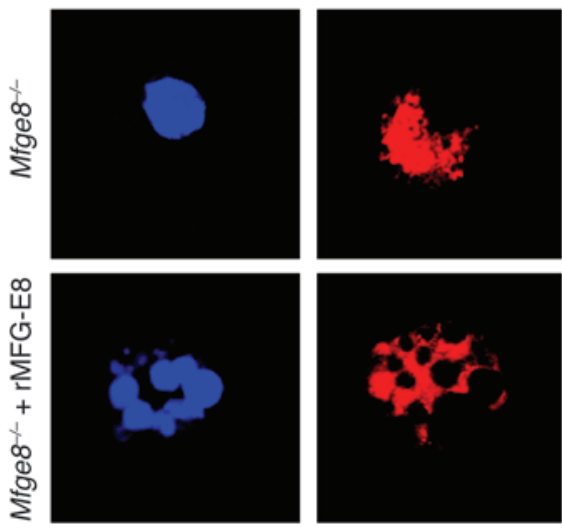

$24 \mathrm{~h}$
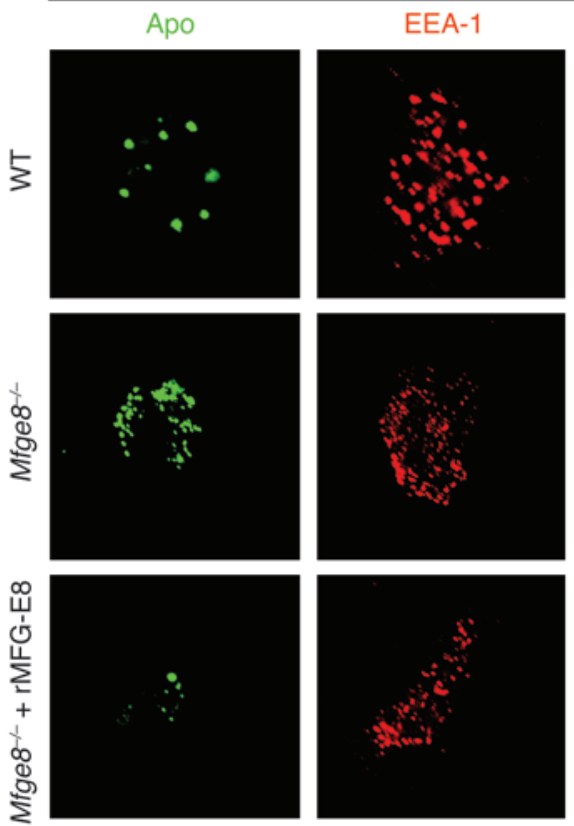
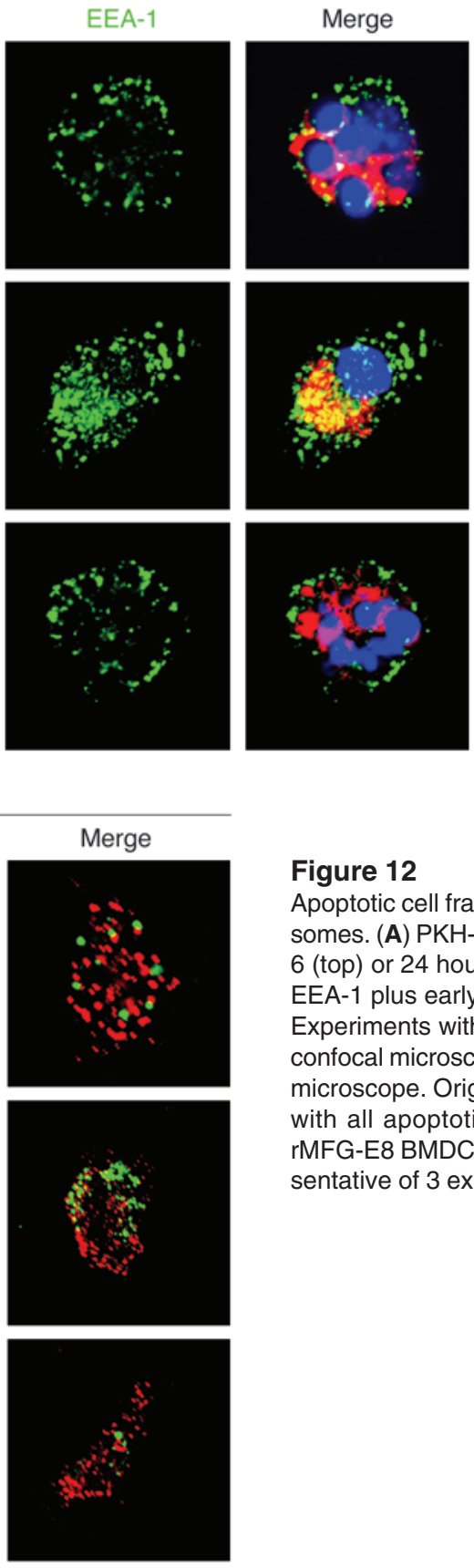

endosomes (37), we further determined whether cell debris in $M f g e 8^{-/-}$DCs remained in early endosomes using the early endosomal marker EEA-1. Although intact apoptotic cells in WT DCs were positive for EEA-1 at the initial stage of uptake (Supplemental Figure 9D), EEA-1-positive early endosomes were no longer associated with apoptotic cells after 6 hours (Figure 12A). In contrast, more than $50 \%$ of cell debris in $\mathrm{Mfge8^{-/ }}$ DCs was colocalized with EEA-1 at 6 hours after ingestion. However, both digested apoptotic cells in WT DCs and cell debris in $M f g e 8^{-/-}$DCs were separated from EEA-1-positive endosomes at 24 hours (Figure 12A), indicating continuous maturation of phagosomes in both DCs. In conclusion, while the lack of
B
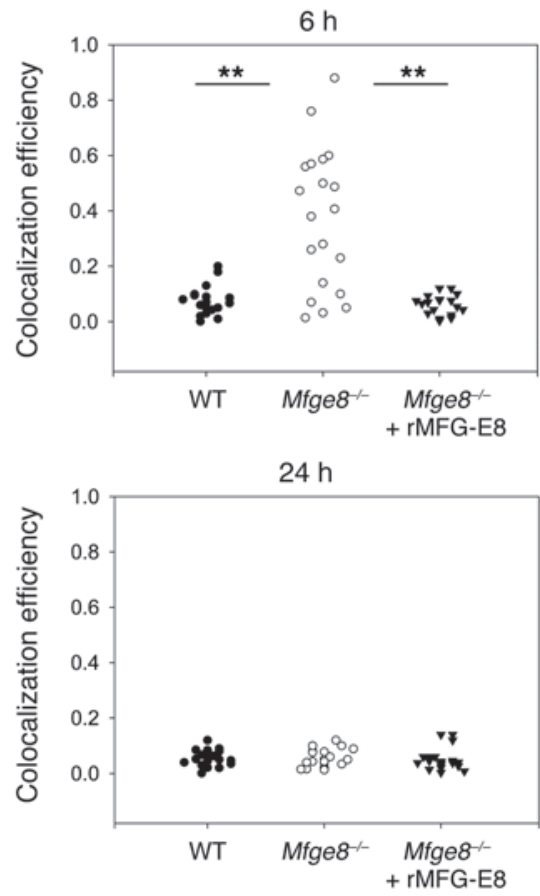

Figure 12

Apoptotic cell fragments in Mfge $8^{-1-}$ DCs persist in EEA-positive endosomes. (A) PKH-labeled apoptotic cells were incubated with BMDCs for 6 (top) or 24 hours (bottom). The colocalization of apoptotic cells and EEA-1 plus early endosomes was visualized by confocal microscopy. Experiments with DAPI staining were analyzed using Zeiss 510 Meta confocal microscope and those without DAPI using Leica SP1 confocal microscope. Original magnification, $\times 400$. (B) Colocalization of EEA-1 with all apoptotic cell material in WT, $\mathrm{Mfge}^{-/-}$, and $\mathrm{Mfge}^{-/-}$plus rMFG-E8 BMDCs at 6 and 24 hours after ingestion. Results are representative of 3 experiments. ${ }^{\star \star} P<0.001$. 

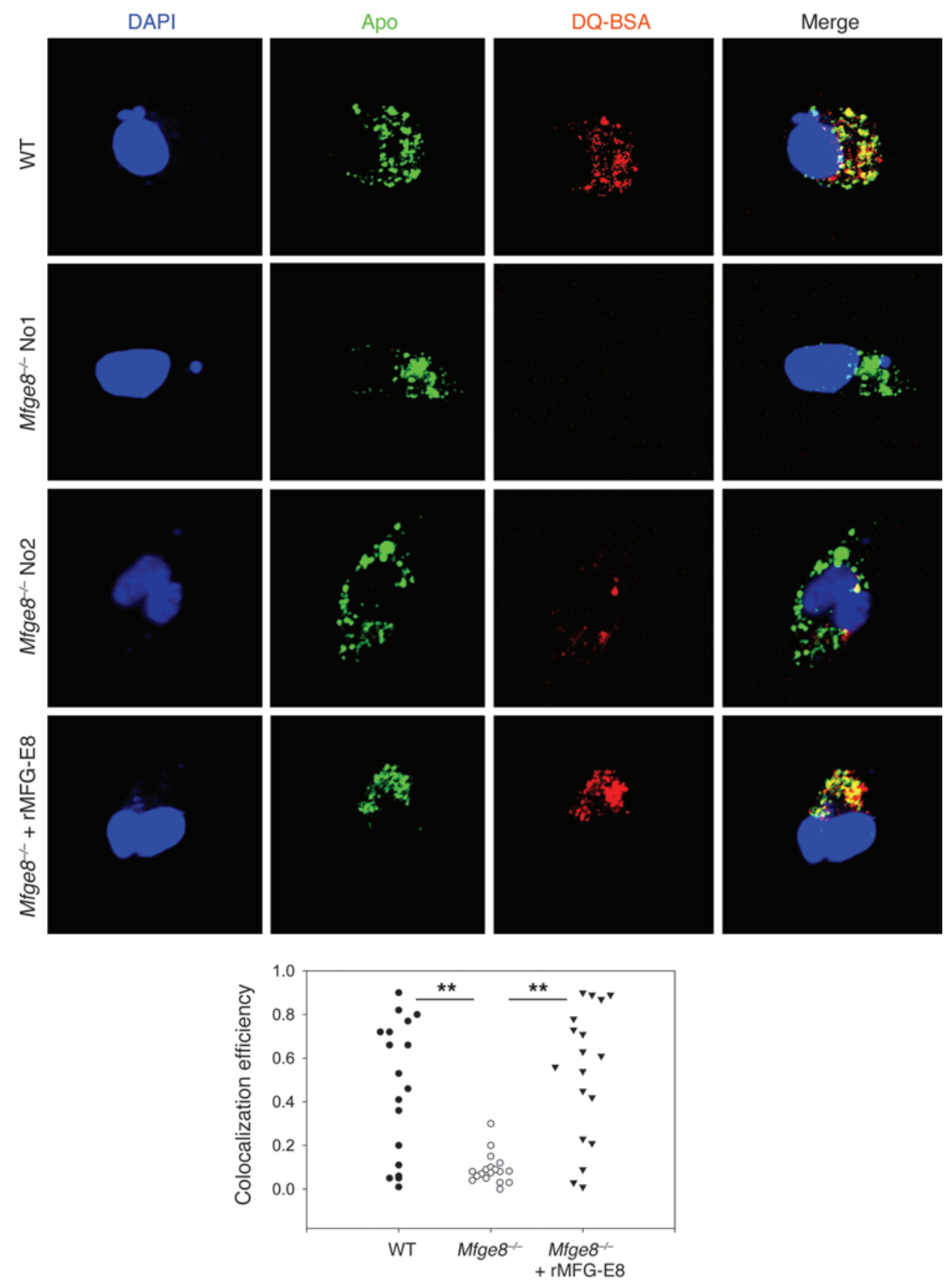

\section{Figure 13}

MFG-E8 deficiency inhibits the proteolytic degradation of apoptotic cellassociated antigen. PKH67-labeled apoptotic cells (green) were coated with DQ-BSA and were added to day6 immature BMDCs from 2-month-old WT or Mfge $8^{-/}$mice. The proteolytic degradation of DQ-BSA produced a red fluorescence and was visualized by confocal microscopy at 20 hours after incubation. Bottom: Colocalization of apoptotic material with DQBSA at 20 hours after incubation. Results are representative of 3 independent experiments. ${ }^{* \star} P<0.001$. Original magnification, $\times 400$. coated apoptotic cells with a more sensitive indicator of proteolytic activity, DQ-BSA (38). Upon proteolytic degradation, the nonfluorogenic DQ-BSA produces a red fluorescence that can be visualized by confocal microscopy. As shown in Figure 13, at 20 hours after incubation, most cell debris were associated with degraded DQ-BSA in WT but not $\mathrm{Mfge} \mathrm{8}^{-/-} \mathrm{BMDCs}$, suggesting antigens associated with apoptotic cells were less prone to degradation in $\mathrm{Mfge}^{-{ }^{-/}}$DCs. To determine whether the improved preservation of antigen can lead to more efficient antigen processing, we utilized antibody 25D1.16 to visualize the specific OVAp/MHCI complex after DCs have ingested Apo-OVA (39). As shown in Figure 14A, although the percentages of DCs that contained OVAp/MHCI complex were similar between WT and $M$ fge $^{-1-}$ DCs at 6 hours after ingestion, the intensity of the complex generated in $M$ fge $^{-/-}$DCs was significantly higher. At 24 hours, 2- to 3-fold more OVAp/MHCI-positive cells were observed in $M f g e 8^{-/-}$DCs (average of 4 experiments). The increased level of OVAp/MHCI in $M f g e 8^{-1-}$ BMDCs was not caused by enhanced expression of MHCI, since adding Apo-OVA to either WT or Mfge $8^{-/-}$ DCs did not affect MHCI levels either at 6 or 24 hours after incubation (Supplemental Figure 10A). The difference between WT

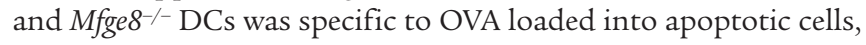
since the same levels of OVAp/MHCI complexes were observed in both cells after incubation with soluble OVA (Supplemental Figure 10B), consistent with the notion that soluble OVA was endocytosed through MFG-E8-independent pathways. Adding LPS to the culture did not increase either the intensity or the percentage of 
A

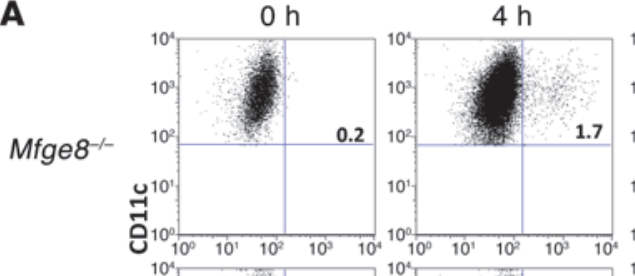

$\mathrm{Oh}$
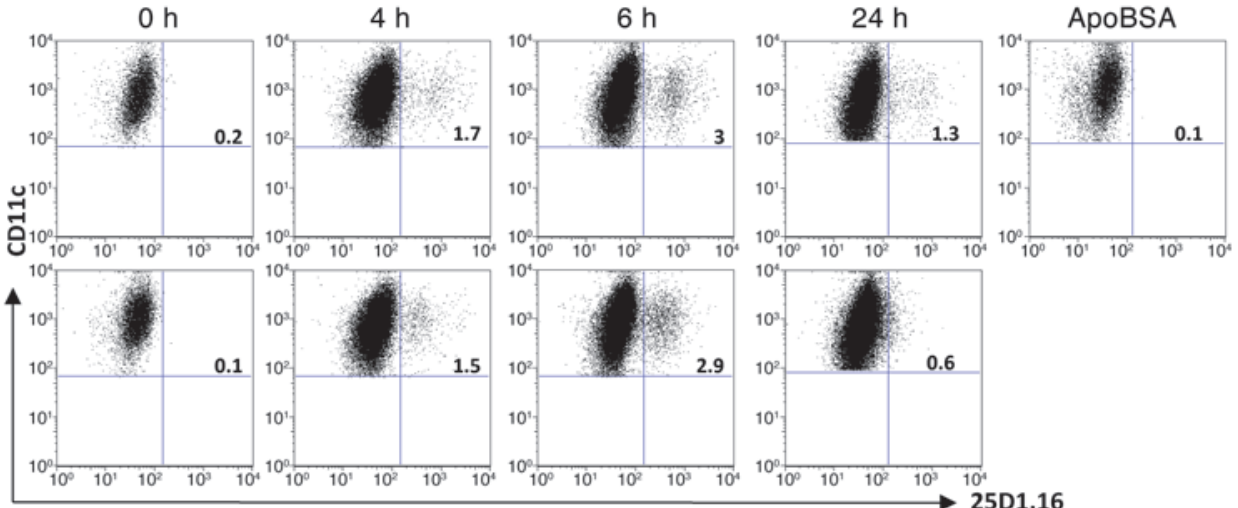

$25 \mathrm{D} 1.16$
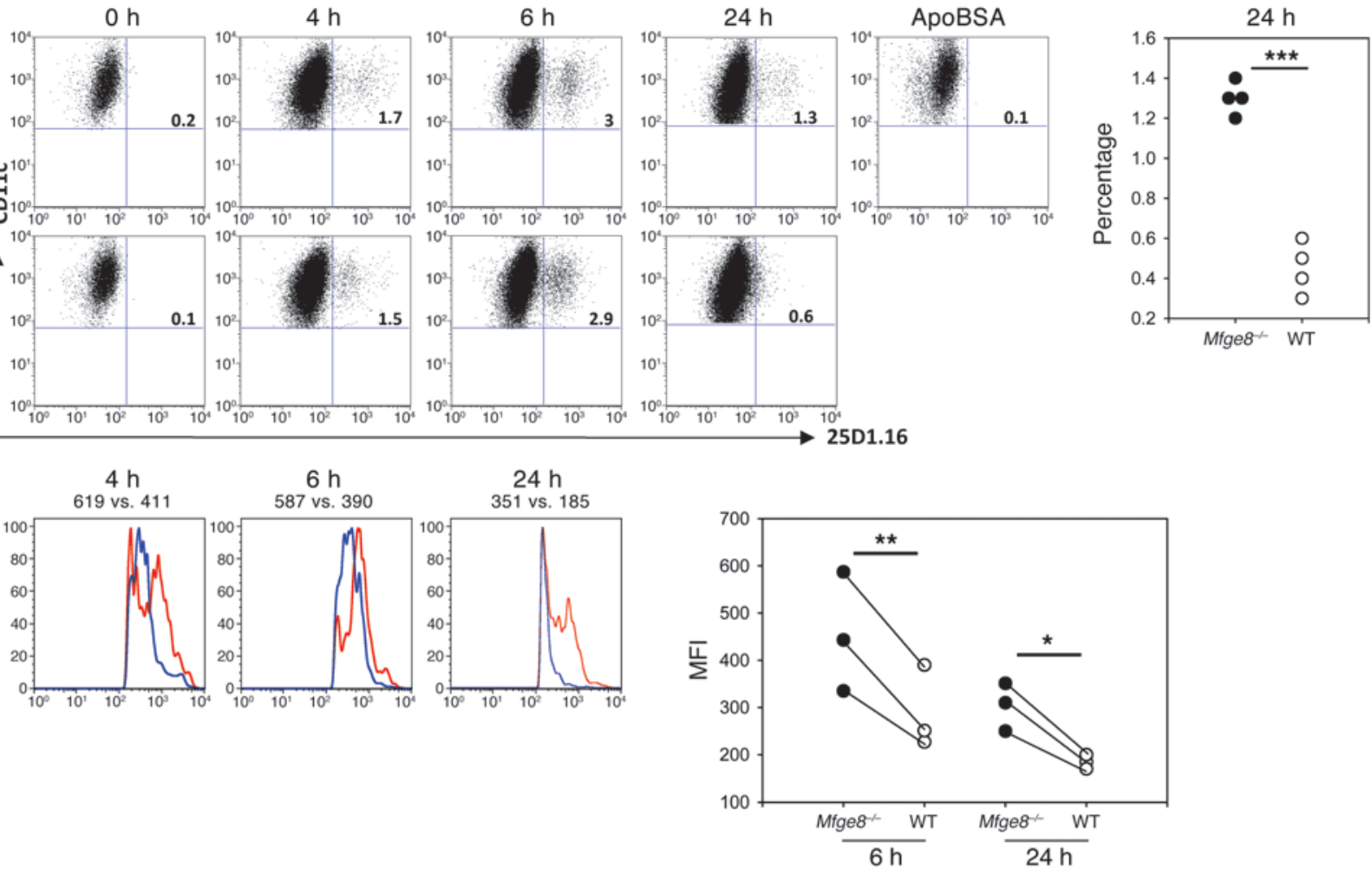

B
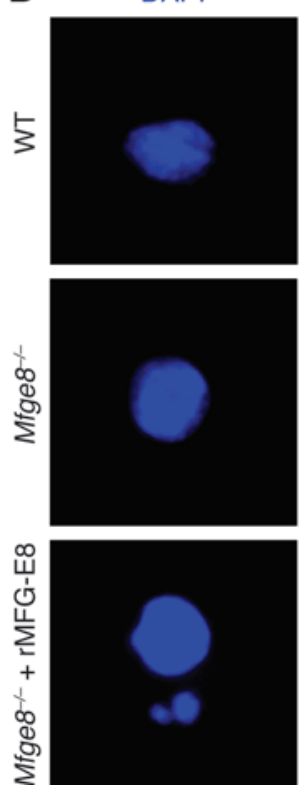

LAMP-1
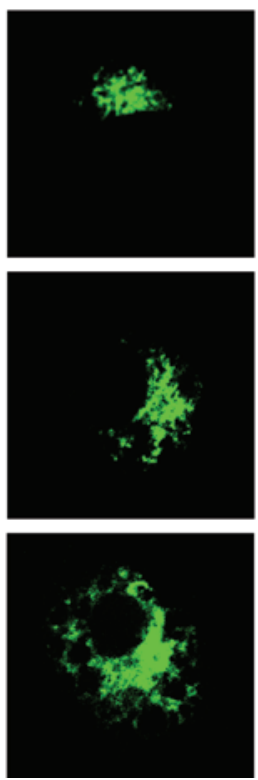

25D1.16
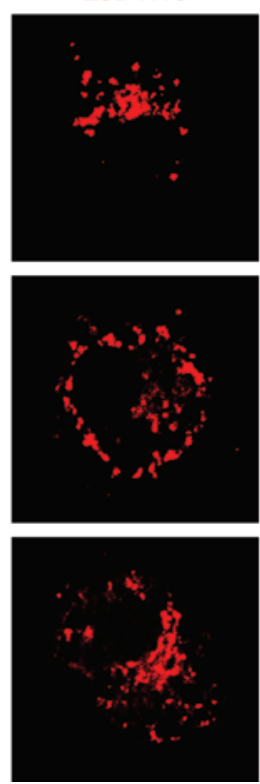

Merge
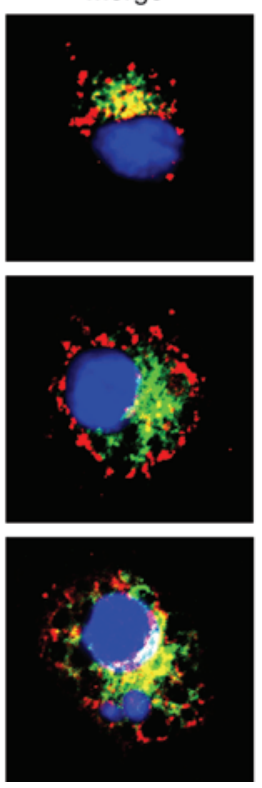

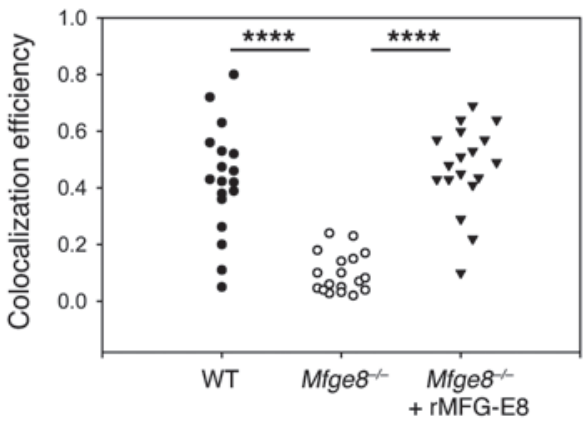

Figure 14

MFG-E8 deficiency enhances the generation of the OVAp/ MHCl complex. (A) Day-6 immature BMDCs were incubated with Apo-OVA for 4, 6, and 24 hours. The generation of OVAp/MHCl complexes was evaluated by intracellular staining with the 25D1.16 antibody and the percentages of 25D1.16+CD11 $\mathrm{C}^{+}$cells shown. Right: percentages of CD11 ${ }^{+} 25 \mathrm{D} 1.16^{+}$cells at 24 hours from 4 independent experiments. ${ }^{* * *} P=0.006$. Histogram below compares the intensities of 25D1.16 staining (histogram: blue, WT; red, Mfge $8^{-/-}$BMDCs). MFIs are shown on the top (Mfge $8^{-/-}$versus WT). Right: results from 3 independent experiments. ${ }^{* \star} P=0.03 ;{ }^{*} P=0.08$, paired $t$ test. Numbers in the dot plots denote the percentages of 25D1.16-positive cells. (B) Left: Apo-OVA were incubated with BMDCs for 6 hours; colocalization of MHCl/OVA peptide complexes and lysosomes was examined by confocal microscopy. The images are representatives of 3 independent experiments with similar results. Right: colocalization of 25D1.16 with LAMP-1. Result is representative of 3 experiments. ${ }^{\star \star \star \star} P<0.001$. Original magnification, $\times 400$. 
A

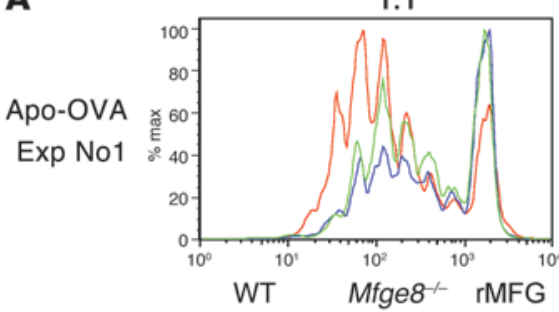

Division index: 0.43
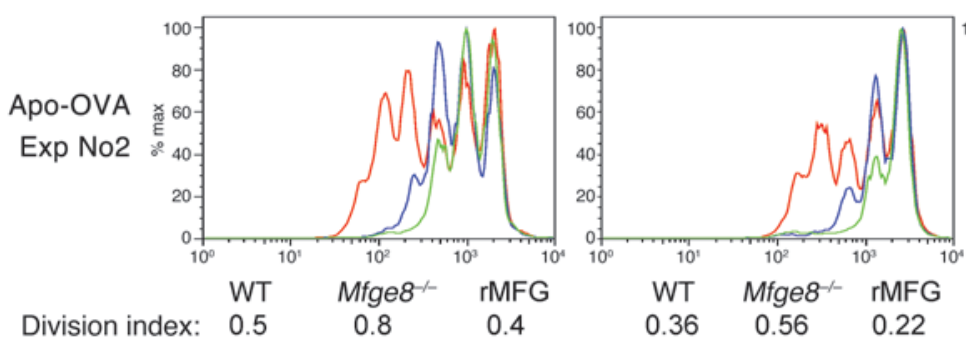

$3: 1$
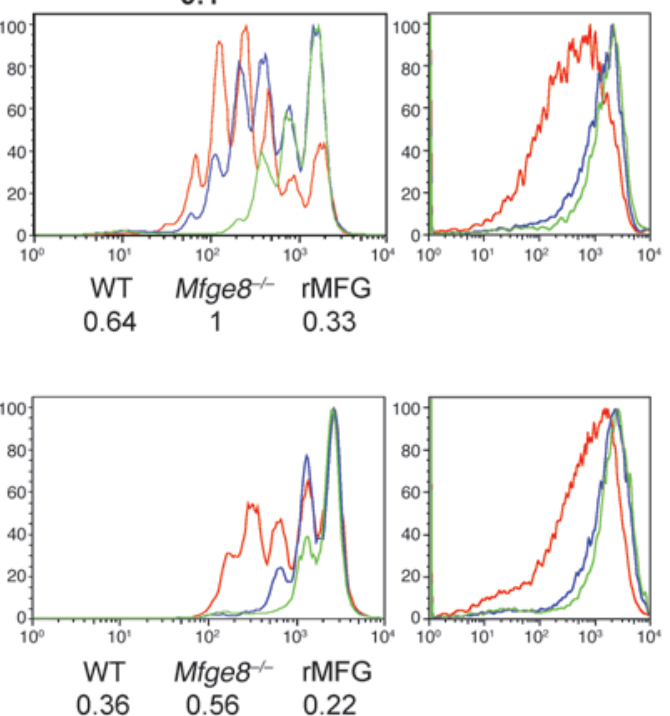

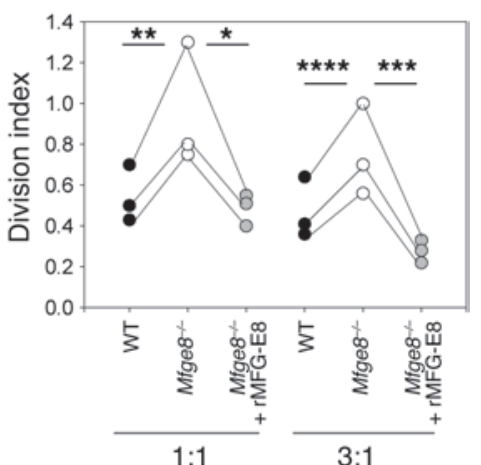

B
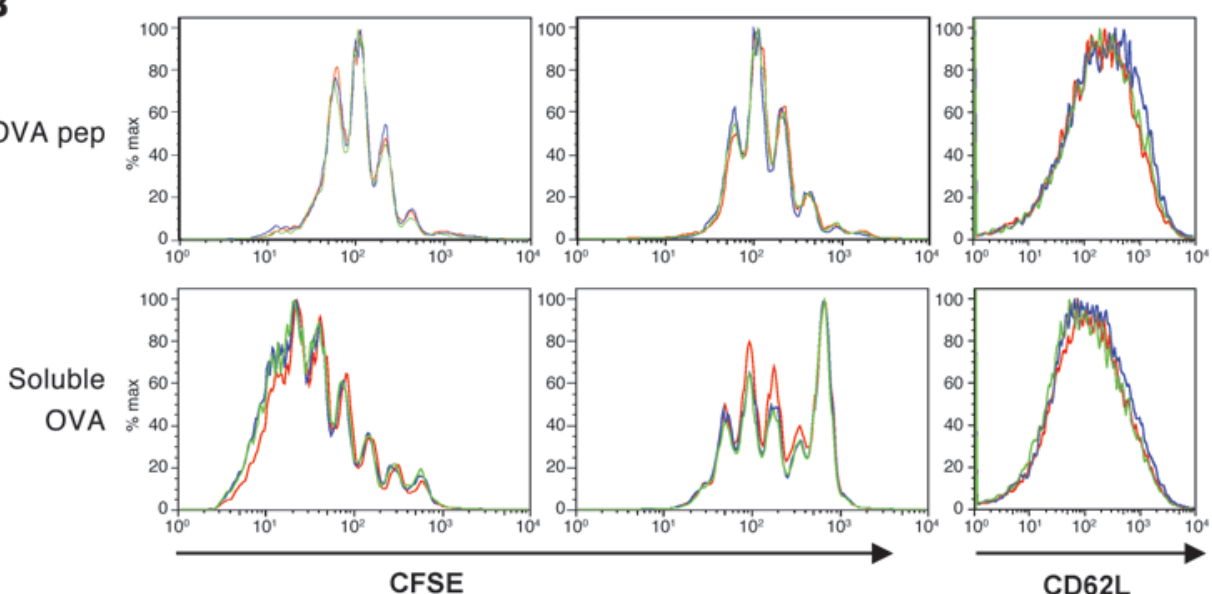

Figure 15

Recombinant MFG-E8 reverses enhanced cross-presentation by Mfge8 $^{-/-}$BMDCs. (A) Day-6 BMDCs from either WT or Mfge8 $8^{-/-}$mice were incubated with Apo-OVA for 24-36 hours. Recombinant MFG-E8 was mixed with apoptotic cells before adding to Mfge $^{-/-}$BMDCs at a final concentration of $0.2 \mu \mathrm{g} / \mathrm{ml}$. Apo-OVA-containing BMDCs were collected to stimulate CFSE-labeled OT-I CD8+ T cells with total DC/T ratios of $1: 1$ and 3:1. OT-I T cell proliferation and CD62L downregulation were analyzed by flow cytometry at day 3 . The results from 2 out of 3 independent experiments are shown. Right: division indices from 3 independent experiments ${ }^{\star \star} P=0.05$, ${ }^{\star} P=0.08$, ${ }^{\star \star \star \star} P=0.025$, ${ }^{\star \star \star} P=0.04$, paired $t$ test. (B) As controls, BMDCs were incubated with either OVA peptide $(10 \mu \mathrm{M})$ for 1 hour or with soluble OVA protein $(200 \mu \mathrm{g} / \mathrm{ml})$ overnight. After washing with medium, DCs were used to stimulate OT-I T cells (red, Mfge8 ${ }^{-/}$BMDCs; green, Mfge8 ${ }^{-/}$BMDCs plus rMFG-E8; blue, WT BMDCs). Both control experiments were performed twice with similar results.

25D1.16-positive cells, presumably due to the impaired uptake by mature DCs (Supplemental Figure 11). In addition to flow cytometry, we next examined the subcellular location of OVAp/MHCI complex using confocal microscopy. Consistent with the observation made with labeled apoptotic cells, most OVAp/MHCI complexes found in $M f g e 8^{-/-}$BMDCs were located outside LAMP-1 ${ }^{+}$ lysosomes (Figure 14B). Importantly, the addition of rMFG-E8 to the $M$ fge $^{-/-}$BMDCs caused relocation of OVAp/MHCI complexes to lysosomes, suggesting accelerated digestion. Consistent with the ability of rMFG-E8 to alter the processing of apoptotic cell material, exogenous MFG-E8 significantly inhibited the stimulatory ability of Apo-OVA-loaded Mfge $8^{-/-}$BMDCs (Figure 15).

\section{Discussion}

Deficiency in many opsonic proteins or their receptors predispose to SLE-like disease in mice $(1,2)$. In the report by Hanayama et al. (18), 40-week-old $\mathrm{Mfge}^{-/-}$mice on the mixed $129 \times \mathrm{C} 57 \mathrm{BL} / 6$ background developed splenomegaly and high-titer ANA antibodies associated with defective uptake of apoptotic cells by tingible body macrophages (18). Although both IgG2c and C3 depositions were detected in older $\mathrm{Mfge}^{-/-}$C57BL/6 mice (Supplemental Figure 12), most of the lupus phenotypes were muted. Instead, we observed an increased frequency of spontaneous dermatitis in older MFG-E8 female mice, possibly caused by the genetic predisposition of C57BL/6 mice to skin disease (40). The spontaneous activation of 

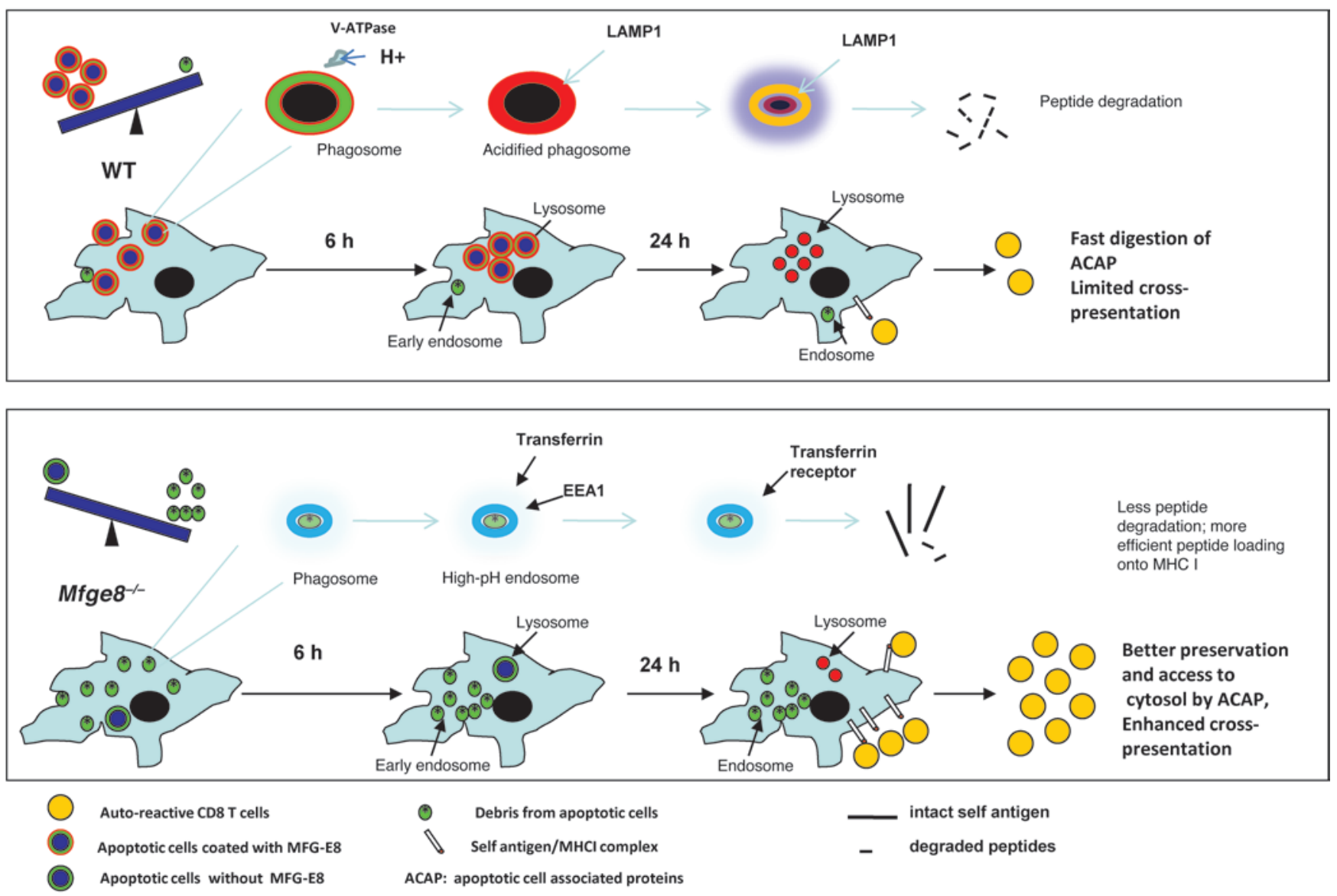

Figure 16

Proposed role of MFG-E8 in facilitating the digestion of apoptotic cell-associated antigens. Top panel: in WT mice, intact apoptotic cells coated with MFG-E8 are swiftly phagocytosed by DCs. Once internalized, the phagosome is acidified by V-ATPase and the membrane of the phagosome begins to fuse with lysosomes. By accelerating acidification and degradation of the apoptotic cell-associated proteins (ACAP), few peptides are available for loading to MHC I and cross presentation is limited (55). Lower panel: in MFG-E8-deficient mice, phagocytosis of intact apoptotic cell is delayed and late apoptotic cells debris start to accumulate. As a result, a large percentage of ingested material in $M f g e 8^{-/-} \mathrm{DCs}$ comprises cell debris. Cell debris persist in endosomal compartments, improving the preservation of ACAP. This, in turn, facilitates self-peptide access to the cross-presentation machinery in the cytosol and enhanced activation of self-reactive CD8 ${ }^{+} \mathrm{T}$ cells in $\mathrm{Mfge}^{-/-}$mice.

$\mathrm{CD}^{+} \mathrm{T}$ cells in $\mathrm{Mfge}^{-/-}$mice and $\mathrm{CD}^{+} \mathrm{T}$ cell infiltration in their skin suggested that $\mathrm{CD} 8^{+} \mathrm{T}$ cells were activated by self antigens. We therefore focused on the $\mathrm{CD}^{+} \mathrm{T}$ cell response to apoptotic cell-associated antigens in this report.

$\mathrm{CD}^{+} \mathrm{T}$ cells respond to apoptotic cell antigens following crosspresentation by APCs (16). Exogenously injected apoptotic cells are ingested by both marginal zone (MZ) macrophages and DCs (41). Although MZ APCs do not express MFG-E8 (19), apoptotic cells are presumably coated with MFG-E8 secreted by FDCs in germinal centers prior to their uptake in MZs $(42,43)$. The enhanced OT-I T cell responses to injected Apo-OVA in $M f g e 8^{-/}$mice implied more efficient cross-presentation by APCs in vivo. To examine this possibility in a more physiological model, we used RIP-mOVA mice, in which apoptotic OVA-expressing $\beta$ cells are ingested by DCs and transported to draining LNs. OT-I T cells that encounter OVA-bearing APCs are then activated and infiltrate the pancreas to induce diabetes (24).

Transfer of OT-I cells to RIP-mOVA-Mfge $8^{-/-}$mice accelerated diabetes associated with increased numbers of IFN- $\gamma$-positive $\mathrm{CD}^{+} \mathrm{T}$ effector cells, indicating that cross-presentation of apop- totic cell-associated OVA is enhanced by MFG-E8 deficiency in vivo. To overcome the limitation of very small numbers of APCs recovered from pancreatic LNs, we crossed $M$ fge $8^{-/-}$with K-mOVA mice that express OVA under control of the keratinocyte K14 promoter. In K-mOVA mice, Langerhans cells, which are known to secrete MFG-E8, constitutively phagocytose OVA-expressing apoptotic keratinocytes (28). Migrating Langerhans cells and other dermal DCs $\left(\mathrm{CD} 8 \alpha^{-}, \mathrm{CD} 103^{+}, \mathrm{DEC} 205^{+}\right)$carry OVA antigen to the draining LNs (26). The relatively large number of APCs recovered from skin-draining LNs enabled us to directly demonstrate more efficient cross-presentation by APCs with MFG-E8 deficiency, even at an age where no obvious dermatitis was evident. Collectively, our results showed MFG-E8 deficiency leads to a greater capacity of APCs to cross-present apoptotic cell-associated antigen.

It is generally thought that defective clearance of apoptotic cells leads to activation of APCs through postapoptotic necrosis with resulting inflammatory responses (5), although precisely how this occurs is not clear. In our experiments, at the ages that mice were examined ( 2 months to 1 year), we did not detect upregulation 
of costimulatory molecules in APCs obtained from either the spleens or the LNs of $M$ fge $8^{-/-}$mice (Supplemental Figures 5 and $6)$. Furthermore, we did not detect any increase of inflammatory cytokines such as IL-12 or TNF- $\alpha$ in the spleens of $M$ fge $^{-1-}$ mice by mRNA array expression analysis (Supplemental Figure 7). The enhanced APC function in $\mathrm{Mfge8^{-/- }}$ mice could also be the result of increased numbers of activated APCs, but this was not observed.

We next considered whether MFG-E8 deficiency could enhance the processing of apoptotic cell-associated antigens using BMDCs. After capturing apoptotic cells, DCs digest cell debris to generate antigenic peptides that can be recognized by $\mathrm{T}$ cells (16). Consistent with previous reports (28), early uptake of intact apoptotic cells was significantly impaired by MFG-E8 deficiency and this defect was corrected by the addition of recombinant MFG-E8. Although the ingestion of apoptotic cells appeared similar between $\mathrm{Mfge}^{-/-}$and WT mouse BMDCs after 1 hour, the composition of the apoptotic material differed significantly between WT and $M$ fge $8^{-/-}$DCs. Whereas WT BMDCs contained predominantly intact apoptotic cells with a few small fragments, the opposite was observed in $M$ fge $8^{-/-}$BMDCs. In agreement with previous reports $(30,32)$, we observed that, in WT BMDCs, apoptotic cell-containing phagosomes matured (were acidified and fused with lysosomes) within 6 hours after ingestion. In contrast, phagosomes containing small cell fragments in $M f g e 8^{-/-}$ mice remained outside of lysosomes even at 24 hours after ingestion. The lack of phagosome maturation in $\mathrm{Mfge}^{-/-} \mathrm{BMDCs}$ was not due to reduced LAMP-1 expression, since both flow cytometry and immunofluorescence staining showed similar expression patterns between WT and $\mathrm{Mfge}^{\mathrm{r}^{-/-}}$BMDCs (our unpublished observations). Although acidification of phagosomes precedes fusion, fusion between phagosomes and lysosomes provides the necessary environment for hydrolytic enzymes to digest particles (34). Interestingly, phagosomes must express signals to trigger and guide the fusion (34), which may be lacking in phagosomes containing cell debris.

The superior ability of DCs to present antigen can be attributed to their ability to store antigen for a longer period of time than macrophages (16). The persistence of antigens influences the duration of the engagement between APCs and T cells or $\mathrm{B}$ cells. While prolonged interaction is required for productive $\mathrm{T}$ cell immunity, transient contact often leads to abortive anergic responses (44). The impaired uptake of intact apoptotic cells caused by MFG-E8 deficiency is associated with the persistence of apoptotic cell debris outside lysosomes in DCs. Taken together with the increased intensity of the OVAp/MHCI complex observed in $M$ fge $^{-/-}$BMDCs by flow cytometry, these results strongly suggest that the altered processing is responsible for enhanced antigen presentation and increased $\mathrm{CD}^{+} \mathrm{T}$ cell responses.

The effect of subcellular location on the presentation of apoptotic cell-associated antigens has not previously been investigated. The route of antigen processing is known to impact adaptive immune responses (45). For example, mannose receptor (MR) diverts OVA from lysosomes to early endosomal compartments and is required for cross-presentation to OT-I CD8 ${ }^{+} \mathrm{T}$ cells by immature DCs. In contrast, lysosomal targeting of antigen is necessary for the activation of OT-II CD4 ${ }^{+} \mathrm{T}$ cells (31). In a recent study, Belizaire and Unanue (36) demonstrated that antigens specifically delivered to the lysosomal compartment through a PS liposome prevented MHC class I cross-presentation, while those targeted to early endosomal compartments via DOPE could be presented on both MHC I and II molecules. The reason that early endosomal location favors the MHC I pathway in both cases could be attrib- uted to a better access to class I processing and loading machinery in the cytosol (36). Since thioglycolate-elicited macrophages used in the study secrete large amounts of MFG-E8 (19), it is likely that PS liposomes would be coated with MFG-E8. These observations are therefore consistent with our findings that MFG-E8 binds to PS on apoptotic cell surfaces, facilitates their removal and digestion, reduces MHC class I cross-presentation, and prevents excessive activation of $\mathrm{CD}^{+} \mathrm{T}$ cells to self antigens.

Enhanced antigen presentation by $M$ fge $8^{-/-}$APCs is also likely to promote the differentiation of $\mathrm{CD} 62 \mathrm{~L}^{\mathrm{lo}} \mathrm{CD}^{+} \mathrm{T}$ cells. During viral infection, antigen-specific $\mathrm{CD}^{+} \mathrm{T}$ cells can be divided into central and effector memory subsets based on their expression of CD62L (21). CD62L plays an important role in $\mathrm{CD}^{+} \mathrm{T}$ cell migration to secondary lymphoid organs (21). CD62 L ${ }^{\text {lo }}$ effector memory T cells recovered from nonlymphoid tissues provide immediate antiviral responses including faster kinetics of IFN- $\gamma$ production (46). Consistent with the preferential accumulation of $\mathrm{CD} 62 \mathrm{~L}^{\text {lo }} \mathrm{CD} 8^{+} \mathrm{T}$ cells in $M$ fge $^{-/-}$mice, the absence of MFG-E8 in RIP-mOVA mice was associated with increased $\mathrm{T}$ cell infiltration in the pancreas. Thus, the enhanced function of APCs in MFG-E8-deficient mice also contributed to entry of $\mathrm{CD}^{+} \mathrm{T}$ cells into target organs. Curiously, a subpopulation of $\mathrm{CD} 44^{-} \mathrm{CD} 62 \mathrm{~L}^{\text {lo }}$ cells was observed in $\mathrm{Mfge8^{-/- }}$ mice. Since most of these cells recovered their CD62L expression after overnight culture (data not shown), the shedding of CD62L on this population is likely to be mediated by $\mathrm{T}$ cell-extrinsic factors. Although the genesis of these cells is not clear, it will be interesting to determine whether the loss of MFG-E8 leads to increased TNF- $\alpha$-converting enzyme (TACE) activity in DCs.

MFG-E8-deficient mice on a mixed C57BL/ $6 \times 129$ genetic background develop a lupus-like disease that is generally associated with abnormal CD4 help to B cells. However, increased $\mathrm{CD}^{+} \mathrm{T}$ cell activation and cytotoxicity have also been reported in SLE and implicated in the further generation of apoptotic cell-related antigens $(47,48)$. Tsokos and colleagues have suggested that, in SLE, activated $\mathrm{CD}^{+} \mathrm{T}$ cells generate double-negative (DN) T cells that can provide help to anti-DNA-producing B cells and infiltrate the kidneys of patients with $\operatorname{SLE}(49,50)$. Recently, a genetic study has linked hyperactive $\mathrm{CD}^{+} \mathrm{T}$ cells to the poor prognosis of a subset of SLE patients (51). Therefore, $\mathrm{CD}^{+} \mathrm{T}$ cells may play an important pathogenic role in systemic as well as organ-specific diseases.

Insulin-specific $\mathrm{CD}^{+} \mathrm{T}$ cells are the first population to infiltrate islets in NOD mice (52). The destruction caused by these cells provides a significant source of self antigen. Interestingly, defective clearance of apoptotic cells by macrophages was reported in NOD mice (53), and crossing Mer deficiency into NOD background greatly accelerated the progression of diabetes (54). Together with our results in $M$ fge $^{-/-}$RIP-mOVA mice, these observations suggest that $\mathrm{T}$ cell activation induced by abnormal uptake and/or processing of apoptotic cell-associated self antigens contributes to both systemic and organ-specific autoimmunity.

Unlike intact apoptotic cells and other particles, how smaller cell fragments are phagocytosed by APCs has not been examined. The divergent fates between intact apoptotic cells and debris suggest they are phagocytosed through different pathways. Whether this pathway is mediated through macropinocytosis, by other PS receptors such as TIM4, or by non-PS receptors such as Mer kinase or CD36, scavenger receptors are under further investigation.

Based on our observations, we propose that when the uptake of intact apoptotic cells becomes defective, such as in MFG-E8 deficiency, the relative proportion of cell debris ingested by phagocytes 
increases. While phagosomes containing intact apoptotic cells fuse with acidic lysosomes and their contents are digested, those containing cell debris remain outside of lysosomes. The increase of apoptotic cell-associated antigens outside lysosomes improves the preservation of antigens, facilitates their access to the crosspresentation machinery in cytosol (55), and leads to enhanced $\mathrm{CD}^{+} \mathrm{T}$ cell responses (Figure 16). Therefore, apoptotic cell-binding opsonins, such as MFG-E8, not only control the rate of ingestion of dying cells, but also the subsequent processing and fate of self antigens displayed on APC surfaces. Defective maturation of phagosomes containing cell debris in $\mathrm{Mfge}^{-{ }^{-/}}$mice suggests a new pathway whereby opsonins of apoptotic cells prevent autoimmunity. Whether C1q, IgM, and GasS have similar effects on the disposal of apoptotic cells is worthy of future examination.

\section{Methods}

Mice and reagents. Mice deficient in $M f g e 8^{-/-}(18)$ or mice transgenic for expression of mOVA under the K14 keratinocyte promoter (K-mOVA, C57BL/ 6 background (25)) and rat insulin promoter (RIP-mOVA, C57BL/6 background) (24) as well as the OT-1 $\mathrm{CD}^{+}$transgenic line were provided by S. Nagata (Kyoto University, Kyoto, Japan), S. Katz (NIH, Bethesda, Maryland, USA), and M. Bevan (University of Washington), respectively. MFG-E8 mice were bred for 12 generations to C57BL/ 6 mice. More than $50 \%$ of MFG-E8 female mice developed spontaneous dermatitis after 1 year; these mice were euthanized according to institutional recommendation. All procedures were approved by the Institutional Animal Care and Use Committee (IACUC) of the University of Washington.

Antibodies against CD8 (53.68), CD44 (IM7), CD62L (MEL-14), IFN- $\gamma$ (XMG.1), CD45.1 (A20), CD11b (M1/70), CD11c (N418), DEC 205 (NLDC145), CD103 (2E7), and CD71 (RI7127) were from Biolegend. 25D1.16 specific for OVA peptide MHC I complex was from eBioscience. LysoTracker red DDN-99 and Alexa Fluor 488-labeled transferrin were from Invitrogen. Alexa Fluor 488-labeled and biotinylated LAMP-1 (ebio1D4B) were from eBioscience. Polyclonal rabbit anti-EEA-1 was from Sigma-Aldrich. Recombinant MFG-E8 was from R\&D Systems. Anti-MFG-E8 (clone 2422) was from MBL.

Depletion of LPS from OVA protein. OVA protein was depleted of LPS by the Triton-X 100 procedure (56), so that the final endotoxin was less than $0.6 \mathrm{EU}$ as determined by the LAL test (E-TOXATE; Sigma-Aldrich).

Cross-presentation of apoptotic cell-associated OVA to OT-I T cells in vivo. $2 \times 10^{6}$ or $2 \times 10^{5} \mathrm{CD} 45.1 / \mathrm{CD} 45.2$ OT-I T cells were negatively selected, labeled with CFSE, and transferred into 2-month-old WT or MFG-E8-deficient mice (CD45.2). LPS-depleted OVA was loaded into apoptotic cells (ApoOVA) by osmotic shock (57), followed by exposure to UV cross-linker $\left(50 \mathrm{~mJ} / \mathrm{cm}^{2}\right)$. After overnight incubation, more than $90 \%$ of cells were apoptotic $\left(\right.$ annexin $\mathrm{V}^{+}$). 1 day after transfer, the recipients were challenged with 20 to $30 \times 10^{6}$ Apo-OVA. At day 9 after challenge, spleen cells were restimulated with OVA peptide (aa 257-264) for 6 hours, the number of OT-I cell was enumerated using the congenic marker, and the expression of IFN- $\gamma$ by OT-I T cells was analyzed by flow cytometry.

OT-I T cell-induced diabetes in the RIP-mOVA model. Mfge $8^{-/-}$mice were crossed to RIP-mOVA mice (C57BL/6 background). $5 \times 10^{6} \mathrm{CD} 45.1 / \mathrm{CD}$ 45.2 OT-I T cells were transferred into 2- to 4-month-old WT or Mfge $8^{-/-}$RIP-mOVA mice. Development of diabetes was monitored daily using Diastix (Bayer) beginning at day 3 after transfer. To analyze OT-I $\mathrm{T}$ cell proliferation and IFN- $\gamma$ production, OT-I T cells were labeled with CFSE prior to transfer. Lymphocytes from pancreatic-draining LNs and distal LNs were recovered at day 7 after transfer and restimulated in vitro with OVA peptide, and the expression of IFN- $\gamma$ by OT-I T cells was analyzed by flow cytometry.
Presentation of skin OVA antigen by endogenous APCs. Mfge8 $8^{-/-}$mice were crossed to K-mOVA mice (C57BL/6 background). Skin-draining LNs were collected from either $\mathrm{Mfge}^{+/-}$or $\mathrm{Mfge} \mathrm{8}^{-/-} \mathrm{K}$-mOVA mice at 2 to 4 months after birth. None of the $M$ fge $8^{-/} \mathrm{K}$-mOVA mice had developed clinical dermatitis at the time of the experiment. $\mathrm{CD} 11 \mathrm{c}^{+}$and $\mathrm{CD} 11 \mathrm{~b}^{+} \mathrm{APCs}$ from skin-draining LNs were selected by positive magnetic sorting using a cocktail containing biotinylated anti-CD11c and anti-CD11b, followed by streptavidin beads (Miltenyi Biotec). Increasing numbers of APCs were incubated with $2 \times 10^{5}$ OT-I T cells. T cell proliferation was evaluated by adding $\left[{ }^{3} \mathrm{H}\right]$-thymidine at day 3 , and IFN- $\gamma$ level in the supernatant was quantified by ELISA. In sorting experiments, DCs from skin-draining LNs were first enriched by positive selection using anti-CD11c and anti-CD11b. Enriched cells were labeled with CD11c, CD8, DEC205, and CD103 and further sorted with FACS aria.

Cross-presentation of Apo-OVA by immature BMDCs in vitro. BMDCs were generated according to standard protocols (58). At day 6, Apo-OVA were added to immature BMDCs at 5:1 ratio. Immature DCs containing apoptotic cells were gently collected at 24-36 hours after incubation and mixed with $5 \times 10^{5}$ CFSE-labeled OT-I T cells at 1:1 and 3:1 total DC/T ratios in a 12-well plate. $\mathrm{T}$ cell proliferation was analyzed by flow cytometry at day 3 . The levels of IFN- $\gamma$ and IL- 2 in the supernatant were evaluated by ELISA. Division index (average number of divisions that a cell that was present in the starting population has undergone) is defined and calculated by FlowJo Software.

Intracellular distribution of apoptotic cell fragments in BMDCs. Thymocyte apoptosis was induced by UV cross-linker $\left(50 \mathrm{~mJ} / \mathrm{cm}^{2}\right)$, followed by overnight incubation. Apoptotic thymocytes were labeled with either PKH67 green or PKH27 red dyes according to the manufacturer's instructions (Sigma-Aldrich). To detect acidification, LysoTracker red was added 30 minutes before apoptotic cells. Labeled apoptotic cells were added to day- 6 immature BMDCs at a 5:1 ratio. DCs were collected at various time points and seeded onto glass slides. Adherent DCs were either washed and examined without fixation with wide-field microscope or fixed with $4 \%$ PFA for confocal microscopy. To detect lysosomes and endosomes, DCs were fixed with $1 \%$ PFA for 10 minutes at room temperature and permeabilized with $0.04 \%$ saponin for 10 minutes. Lysosomes and early endosomes were identified by anti-LAMP- 1 and anti-EEA- 1 staining, respectively. To label endosomes with transferrin, DCs were collected and cultured with serumfree PRMI for 30 minutes, followed by $50 \mu \mathrm{g} / \mathrm{ml}$ Alexa Fluor 488-labeled recombinant transferrin (Invitrogen) in RPMI 1640/1\% BSA for 1 hour. To locate apoptotic cells in the endosomal pathway at later time points, PKH27-labeled cells were incubated with DCs for 24 hours. Cells were collected, fixed, and permeabilized as above. Transferrin receptor was detected using anti-CD71 antibody. To evaluate the degradation of antigens associated with apoptotic cells, $20 \times 10^{6} \mathrm{PKH} 67$-labeled apoptotic thymocytes (green) were coated with $200 \mu \mathrm{l}$ DQ-BSA ( $1 \mathrm{mg} / \mathrm{ml}$ ) (Invitrogen) for 1 hour at $37^{\circ} \mathrm{C}$. To reverse MFG-E8 deficiency, recombinant MFG-E8 $(0.25 \mu \mathrm{g} / \mathrm{ml})$ was mixed with apoptotic cells before adding to BMDCs (28). Experiments with DAPI staining were analyzed using a Zeiss 510 Meta confocal microscope and those without DAPI using a Leica SP1 confocal microscope.

Processing of apoptotic cell-associated OVA antigen by BMDCs. To detect OVAp/MHCI complex, OVA-loaded apoptotic thymocytes were added to day-6 immature DCs at a 5:1 ratio. DCs were collected at various time points and stained for surface expression of CD11c. Cells were further fixed with $1 \%$ PFA for 10 minutes at room temperature and then permeabilized with $0.04 \%$ saponin for an additional 10 minutes. The intracellular level of OVApep/MHCI complex was evaluated by biotinylated 25D1.16, followed by either streptavidin PE for flow cytometry or streptavidin rhodamine $\mathrm{X}$ (Jackson ImmunoResearch) by confocal microscopy.

Quantification of colocalization and statistics. The colocalization of apoptotic cell material with various markers was quantified with ImageJ Software (rsbweb.nih.gov/ij/). The JACoP plug-in can be downloaded 
(http://rsbweb.nih.gov/ij/plugins/track/jacop.html). M1 and M2 coefficients method was used to calculate the overlapping ratio (59). The maximal colocalization efficiency between 2 markers is 1.0. In each experiment, the colocalization within 15-20 cells was calculated. In colocalization experiments, nonparametric 1-tailed Mann-Whitney $U$ test was used to calculate statistical significance. In other experiments, 1-tailed Student's $t$ test was used to calculate statistical significance unless indicated otherwise. $P<0.05$ was considered statistically significant. All error bars represent SD.

\section{Acknowledgments}

This work was supported by NIH grant AR48796 (to K.B. Elkon). Y.F. Peng was supported by a Career Development grant from the
Arthritis Foundation. We would like to thank Mike Bevan for advice and the O'Brien Lab of University of Washington for photo and slide processing.

Received for publication April 6, 2010, and accepted in revised form March 9, 2011.

Address correspondence to: YuFeng Peng or Keith B. Elkon, Division of Rheumatology, University of Washington, 1959 NE Pacific Street, Box 356428, Seattle, Washington 98195, USA. Phone: 206.616.5636; Fax: 206.685.9397; E-mail: pengyf@u.washington. edu (Y.F. Peng). Phone: 206.543.3415; Fax: 206.685.9397; E-mail: elkon@u.washington.edu (K.B. Elkon).
1. Gaipl US, et al. Clearance of apoptotic cells in human SLE. Curr Dir Autoimmun. 2006;9:173-187.

2. Peng Y, Martin DA, Kenkel J, Zhang K, Ogden CA, Elkon KB. Innate and adaptive immune response to apoptotic cells. J Autoimmun. 2007;29(4):303-309.

3. Li M, et al. Cell-associated ovalbumin is cross-presented much more efficiently than soluble ovalbumin in vivo. J Immunol. 2001;166(10):6099-6103.

4. Batista FD, Iber D, Neuberger MS. B cells acquire antigen from target cells after synapse formation. Nature. 2001;411(6836):489-494.

5. Nagata S, Hanayama R, Kawane K Autoimmunity and the clearance of dead cells. Cell. 2010; 140(5):619-630.

6. Somersan S, Bhardwaj N. Tethering and tickling: a new role for the phosphatidylserine receptor. J Cell Biol. 2001;155(4):501-504.

7. Zhou Z, Yu X. Phagosome maturation during the removal of apoptotic cells: receptors lead the way. Trends Cell Biol. 2008;18(10):474-485.

8. Casciola-Rosen LA, Anhalt G, Rosen A. Autoantigens targeted in systemic lupus erythematosus are clustered in two populations of surface structures on apoptotic keratinocytes. J Exp Med. 1994;179(4):1317-1330.

9. Schiller M, Bekeredjian-Ding I, Heyder P, Blank N, Ho AD, Lorenz HM. Autoantigens are translocated into small apoptotic bodies during early stages of apoptosis. Cell Death Differ. 2008;15(1):183-191.

10. Fadok VA, Bratton DL, Konowal A, Freed PW, Westcott JY, Henson PM. Macrophages that have ingested apoptotic cells in vitro inhibit proinflammatory cytokine production through autocrine/ paracrine mechanisms involving TGF-beta, PGE2, and PAF. J Clin Invest. 1998;101(4):890-898.

11. Shi Y, Evans JE, Rock KL. Molecular identification of a danger signal that alerts the immune system to dying cells. Nature. 2003;425(6957):516-521.

12. Urbonaviciute $V$, et al. Induction of inflammatory and immune responses by HMGB1-nucleosome complexes: implications for the pathogenesis of SLE. J Exp Med. 2008;205(13):3007-3018.

13. Stuart LM, Lucas M, Simpson C, Lamb J, Savill J, Lacy-Hulbert A. Inhibitory effects of apoptotic cell ingestion upon endotoxin-driven myeloid dendritic cell maturation. JImmunol. 2002;168(4):1627-1635.

14. Kim S, Elkon KB, Ma X. Transcriptional suppression of interleukin-12 gene expression following phagocytosis of apoptotic cells. Immunity. 2004;21(5):643-653.

15. Delamarre L, Pack M, Chang H, Mellman I, Trombetta ES. Differential lysosomal proteolysis in antigen-presenting cells determines antigen fate. Science. 2005;307(5715):1630-1634

16. Trombetta ES, Mellman I. Cell biology of antigen processing in vitro and in vivo. Annu Rev Immunol. 2005;23:975-1028.

17. Steinman RM, Turley S, Mellman I, Inaba K. The induction of tolerance by dendritic cells that have captured apoptotic cells. J Exp Med. 2000;
191(3):411-416.

18. Hanayama R, et al. Autoimmune disease and impaired uptake of apoptotic cells in MFG-E8-deficient mice. Science. 2004;304(5674):1147-1150.

19. Hanayama R, Tanaka M, Miwa K, Shinohara A, Iwamatsu A, Nagata S. Identification of a factor that links apoptotic cells to phagocytes. Nature. 2002;417(6885):182-187.

20. Asano K, et al. Masking of phosphatidylserine inhibits apoptotic cell engulfment and induces autoantibody production in mice. J Exp Med. 2004;200(4):459-467.

21. Sallusto F, Geginat J, Lanzavecchia A. Central memory and effector memory $\mathrm{T}$ cell subsets: function, generation, and maintenance. Annu Rev Immunol. 2004;22:745-763.

22. Zheng L, Fisher G, Miller RE, Peschon J, Lynch $\mathrm{DH}$, Lenardo MJ. Induction of apoptosis in mature T cells by tumour necrosis factor. Nature. 1995;377(6547):348-351.

23. Blander JM. Phagocytosis and antigen presentation: a partnership initiated by Toll-like receptors. Ann Rheum Dis. 2008;67(suppl 3):iii44-iii49.

24. Kurts C, Heath WR, Carbone FR, Allison J, Miller $\mathrm{JF}$, Kosaka H. Constitutive class I-restricted exogenous presentation of self antigens in vivo. J Exp Med. 1996;184(3):923-930.

25. Shibaki A, Sato A, Vogel JC, Miyagawa F, Katz SI. Induction of GVHD-like skin disease by passively transferred CD8(+) T-cell receptor transgenic T cells into keratin 14-ovalbumin transgenic mice. J Invest Dermatol. 2004;123(1):109-115.

26. Bedoui $S$, et al. Cross-presentation of viral and self antigens by skin-derived CD103+ dendritic cells. Nat Immunol. 2009;10(5):488-495.

27. Henri S, et al. CD207+ CD103+ dermal dendritic cells cross-present keratinocyte-derived antigens irrespective of the presence of Langerhans cells. J Exp Med. 2010;207(1):189-206.

28. Miyasaka K, Hanayama R, Tanaka M, Nagata S. Expression of milk fat globule epidermal growth factor 8 in immature dendritic cells for engulfment of apoptotic cells. Eur J Immunol. 2004; 34(5):1414-1422.

29. Badovinac VP, Haring JS, Harty JT. Initial T cell receptor transgenic cell precursor frequency dictates critical aspects of the CD8(+) T cell response to infection. Immunity. 2007;26(6):827-841.

30. Blander JM, Medzhitov R. Regulation of phagosome maturation by signals from toll-like receptors. Science. 2004;304(5673):1014-1018.

31. Burgdorf S, Kautz A, Bohnert V, Knolle PA, Kurts C. Distinct pathways of antigen uptake and intracellular routing in CD4 and CD8 T cell activation. Science. 2007;316(5824):612-616.

32. Erwig LP, McPhilips KA, Wynes MW, Ivetic A, Ridley AJ, Henson PM. Differential regulation of phagosome maturation in macrophages and dendritic cells mediated by Rho GTPases and ezrinradixin-moesin (ERM) proteins. Proc Natl Acad Sci

\section{US A. 2006;103(34):12825-12830}

33. Blocker A, et al. Molecular requirements for bidirectional movement of phagosomes along microtubules. J Cell Biol. 1997;137(1):113-129.

34. Vieira OV, Botelho RJ, Grinstein S. Phagosome maturation: aging gracefully. Biochem J. 2002;366(pt 3):689-704.

35. Blanchette CD, Woo YH, Thomas C, Shen N, Sulchek TA, Hiddessen AL. Decoupling internalization, acidification and phagosomal-endosomal/lysosomal fusion during phagocytosis of InlA coated beads in epithelial cells. PLoS One. 2009;4(6):e6056.

36. Belizaire R, Unanue ER. Targeting proteins to distinct subcellular compartments reveals unique requirements for MHC class I and II presentation. Proc Natl Acad Sci U S A. 2009;106(41):17463-17468.

37. Cox D, Lee DJ, Dale BM, Calafat J, Greenberg S. A Rab11-containing rapidly recycling compartment in macrophages that promotes phagocytosis. Proc Natl Acad Sci U S A. 2000;97(2):680-685

38. Herber DL, et al. Lipid accumulation and dendritic cell dysfunction in cancer. Nat Med. 2010; 16(8):880-886.

39. Porgador A, Yewdell JW, Deng Y, Bennink JR, Germain RN. Localization, quantitation, and in situ detection of specific peptide-MHC class I complexes using a monoclonal antibody. Immunity. 1997;6(6):715-726

40. Kastenmayer RJ, Fain MA, Perdue KA. A retrospective study of idiopathic ulcerative dermatitis in mice with a C57BL/ 6 background. J Am Assoc Lab Anim Sci. 2006;45(6):8-12.

41. Peng Y, Latchman Y, Elkon KB. Ly6C(low) monocytes differentiate into dendritic cells and cross-tolerize T cells through PDL-1. J Immunol. 2009;182(5):2777-2785.

42. Kranich J, et al. Follicular dendritic cells control engulfment of apoptotic bodies by secreting Mfge8. J Exp Med. 2008;205(6):1293-1302.

43. Yamaguchi $\mathrm{H}$, et al. Milk fat globule EGF factor 8 in the serum of human patients of systemic lupus erythematosus. J Leukoc Biol. 2008;83(5):1300-1307.

44. Hugues S, Fetler L, Bonifaz L, Helft J, Amblard F, Amigorena S. Distinct T cell dynamics in lymph nodes during the induction of tolerance and immunity. Nat Immunol. 2004;5(12):1235-1242.

45. Burgdorf S, Kurts C. Endocytosis mechanisms and the cell biology of antigen presentation. Curr Opin Immunol. 2008;20(1):89-95.

46. Masopust D, Vezys V, Marzo AL, Lefrancois L. Preferential localization of effector memory cells in nonlymphoid tissue. Science. 2001;291(5512):2413-2417.

47. Casciola-Rosen L, Andrade F, Ulanet D, Wong WB, Rosen A. Cleavage by granzyme B is strongly predictive of autoantigen status: implications for initiation of autoimmunity. J Exp Med. 1999;190(6):815-826.

48. Blanco P, Pitard V, Viallard JF, Taupin JL, Pellegrin JL, Moreau JF. Increase in activated CD8+ $\mathrm{T}$ lymphocytes expressing perforin and granzyme $\mathrm{B}$ correlates with disease activity in patients with 
systemic lupus erythematosus. Arthritis Rheum. 2005;52(1):201-211.

49. Crispin JC, Tsokos GC. Human TCR-alpha beta+ CD4- CD8- $\mathrm{T}$ cells can derive from CD8+ T cells and display an inflammatory effector phenotype. J Immunol. 2009;183(7):4675-4681.

50. Shivakumar S, Tsokos GC, Datta SK. T cell receptor alpha/beta expressing double-negative (CD4-/ CD8-) and CD4+ T helper cells in humans augment the production of pathogenic anti-DNA autoantibodies associated with lupus nephritis. J Immunol. 1989;143(1):103-112

51. McKinney EF, et al. A CD8+ T cell transcription signature predicts prognosis in autoimmune disease.
Nat Med. 2010;16(5):586-591.

52. Wong FS, et al. Identification of an MHC class I-restricted autoantigen in type 1 diabetes by screening an organ-specific cDNA library. Nat Med. 1999;5(9):1026-1031.

53. O'Brien BA, et al. A deficiency in the in vivo clearance of apoptotic cells is a feature of the NOD mouse. J Autoimmun. 2006;26(2):104-115.

54. Wallet MA, et al. MerTK is required for apoptotic cell-induced T cell tolerance. J Exp Med. 2008;205(1):219-232.

55. Amigorena S, Savina A. Intracellular mechanisms of antigen cross presentation in dendritic cells. Curr Opin Immunol. 2010;22(1):109-117.
56. Aida Y, Pabst MJ. Removal of endotoxin from protein solutions by phase separation using Triton X114. J Immunol Methods. 1990;132(2):191-195.

57. den Haan JM, Lehar SM, Bevan MJ. CD8(+) but not CD8(-) dendritic cells cross-prime cytotoxic T cells in vivo. J Exp Med. 2000;192(12):1685-1696.

58. Inaba $\mathrm{K}$, et al. Generation of large numbers of dendritic cells from mouse bone marrow cultures supplemented with granulocyte/macrophage colony-stimulating factor. J Exp Med. 1992;176(6):1693-1702.

59. Bolte S, Cordelieres FP. A guided tour into subcellular colocalization analysis in light microscopy. JMicrosc. 2006;224(pt 3):213-232. 